NATYONAL LABORATORY

\title{
Caustic-Side Solvent Extraction Chemical and Physical Properties: Equilibrium Modeling of Distribution Behavior
}

\section{December 2001}

Prepared by

Letitia H. Delmau

Tamara J. Haverlock

Tatiana G. Levitskaia Frederick V. Sloop, Jr Bruce A. Moyer

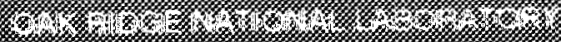

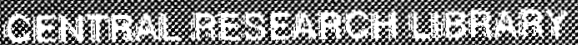

sox.

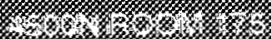

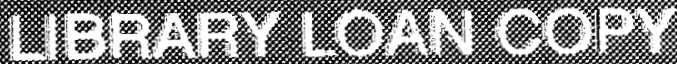

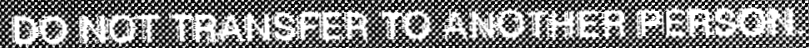

18.

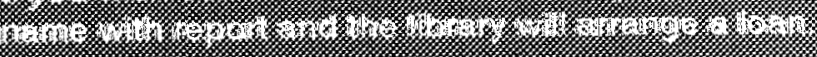

1.6. 


\section{DOCUMENT AVAILABILITY}

Reporis produced after January 1, 1996, are generally available free via the U.S. Department of Energy (DOE) Information Bridge:

Web site: http///www.osti.gov/bridge

Reports produced before January 1, 1996, may be purchased by members of the public from the following source:

National Technical Information Service

5285 Port Royal Road

Springfield, VA 22161

Telephone: 703-605-6000 (1-800-553-6847)

TDD: 703-487-4639

Fax: 703-605-6900

E-mail: info@ntis.fedworld.gov

Web site: http://www.ntis.gov/support/ordernowabout.htm

Reports are available to DOE employees, DOE contractors, Energy Technology Data Exchange (ETDE) representatives, and International Nuclear Information System (INIS) representatives from the following source:

Office of Scientific and Technical Information

P.O. Box 62

Oak Ridge, TN 37831

Telephone: 865-576-8401

Fax: 865-576-5728

E-mail: reports@adonis.osti.gov

Web site: http://www.osti.gov/contact.html

This report was prepared as an account of work sponsored by an agency of the United States Government. Neither the United States government nor any agency thereof, nor any of their employees, makes any warranty, express or implied, or assumes any legal liability or responsibility for the accuracy, completeness, or usefulness of any information, apparatus, product, or process disclosed, or represents that its use would not infringe privately owned rights. Reference herein to any specific commercial product, process, or service by trade name, trademark, manufacturer, or otherwise, does not necessarily constitute or imply its endorsement, recommendation, or favoring by the United States Government or any agency thereof. The views and opinions of authors expressed herein do not necessarily state or reflect those of the United States Government or any agency thereof. 


\section{CAUSTIC-SIDE SOLVENT EXTRACTION CHEMICAL AND PHYSICAL PROPERTIES: EQUILIBRIUM MODELING OF DISTRIBUTION BEHAVIOR}

Lætitia H. Delmau, Tamara J. Haverlock, Tatiana G. Levitskaia, Frederick V. Sloop, Jr., and Bruce A. Moyer

Date Published: December 2001

Prepared by OAK RIDGE NATIONAL LABORATORY

P.O. Box 2008

Oak Ridge, Tennessee 37831-6285 managed by

UT-Battelle, LLC for the

U.S. DEPARTMENT OF ENERGY under contract DE-AC05-00OR22725 



\section{CONTENTS}

$\begin{array}{lll}\text { Page } & \text { Pas }\end{array}$

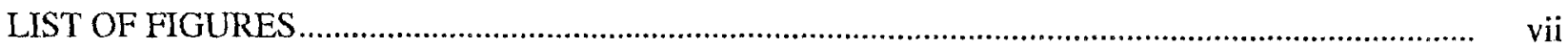

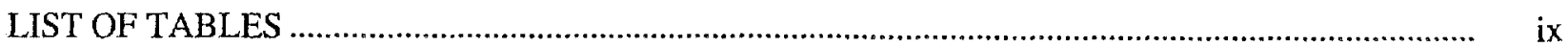

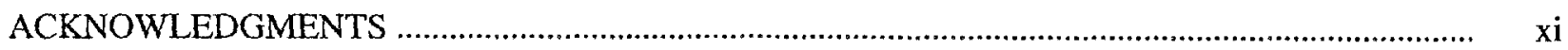

ABSTRACT

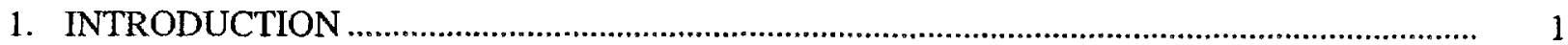

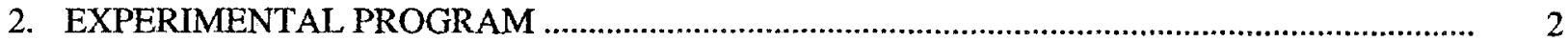

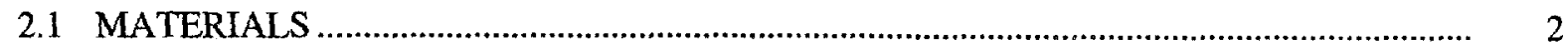

2.2 GENERAL CONTACTING AND COUNTING PROCEDURE …........................................

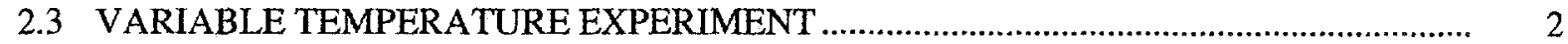

2.4 EXPERIMENTS WITH CALIXARENE-FREE SOLVENT …...........................................

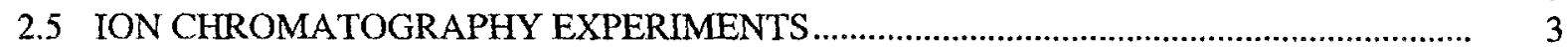

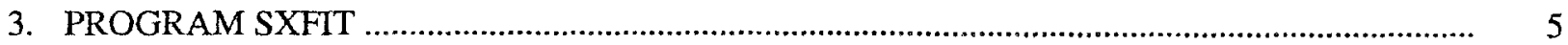

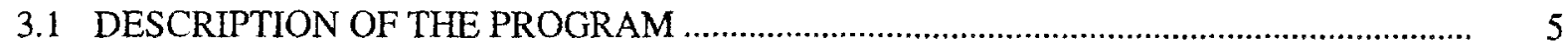

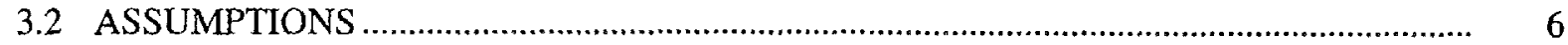

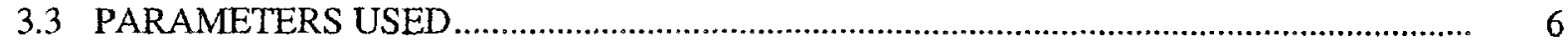

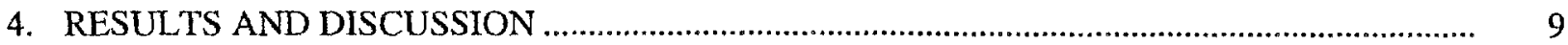

4.1 EXTRACTION MODELING FROM NITRATE MEDIA ….................................................

4.2 EXTRACTION MODELING FROM HYDROXIDE MEDIA …........................................... 11

4.3 EXTRACTION MODELING FROM NITRITE OR CHLORIDE MEDIA ….........................

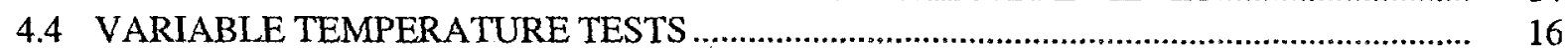

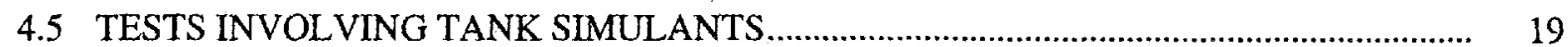

4.6 PREDICTION OF CESIUM EXTRACTION FROM THE FULL SIMULANT .................... 20

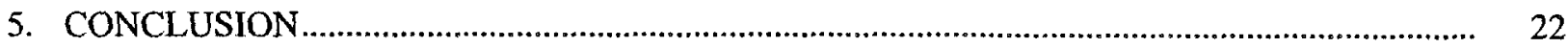

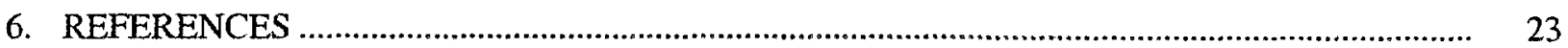

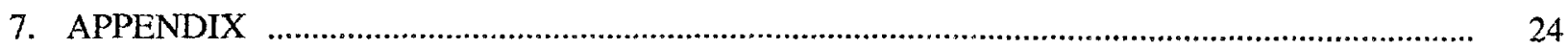




\section{LIST OF FIGURES}

Figure $\quad$ Page

1 Fit of cesium distribution ratios for nitrate media .............................................................. 10

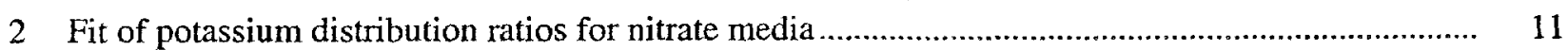

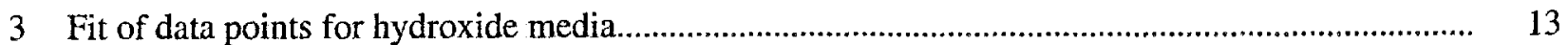

4 Fit of cesium and potassium distribution ratios for chloride media ............................................... 15

5 Fit of cesium and potassium distribution ratios for nitrite media ................................................... 16

6 Fit of cesium distribution ratios for nitrate media at different temperatures................................... 17

7 Fit of cesium distribution ratios for hydroxide media at different temperatures............................... 19 



\section{LIST OF TABLES}

Table

Page

1 Molecular weights and non aqueous molar volumes of the constituents .........................................

2 Masson coefficients of ions present in the system ..............................................................

3 Pitzer parameters for the interactions between ions present in the system ..................................... 8

4 Species and formation constants for the model derived for nitrate data....................................... 9

$5 \quad$ Species and formation constants for the model derived for hydroxide data .................................. 12

6 Species and formation constants for the model derived for nitrite data ........................................ 14

7 Species and formation constants for the model derived for chloride data.................................... 14

8 Formation constant for the model including nitrate data at different temperatures ........................... 18

9 Formation constant for the model including hydroxide data at different temperatures .................... 19

10 Comparison of measured and predicted distribution ratios for tank simulants .............................. 19

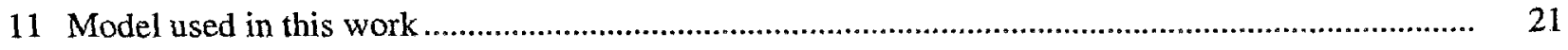





\section{ACKNOWLEDGMENTS}

The authors would like to express their deepest gratitude to Charles F. Baes, Jr for his constant help and advices regarding the program SXFIT. 



\begin{abstract}
A multivariate mathematical model describing the extraction of cesium from different mixtures of sodium hydroxide, sodium nitrate, sodium chloride, and sodium nitrite containing potassium at variable concentrations has been established. It was determined based on the cesium, potassium, and sodium distribution ratios obtained with simple systems containing single salts. These experimental data were modeled to obtain the formation constants of complexes formed in the organic phase based on specified concentrations of components in both organic and aqueous phases. The model was applied to five different SRS waste simulants, and the corresponding cesium extraction results were predicted satisfactorily, thus validating the model.
\end{abstract}

\title{
1. INTRODUCTION
}

The solvent extraction process proposed and considered for cesium removal from the waste present at the Savannah River Site (SRS) is being investigated with respect to the behavior of system components under different conditions. A thorough understanding of the process is in part demonstrable by establishing a model that predicts the extraction of cesium based on the major components of the waste (or simulant). The ability to predict distribution behavior facilitates appropriate flowsheet design to accommodate changing feed composition and temperature. It also provides greater confidence in the robustness of the process overall. Finally, given the knowledge of the composition of any particular feed, a reliable model yields an immediate estimate of expected flowsheet performance for comparison with process data. The scope of this modeling study was directed toward predicting the cesium distribution ratios obtained with five different SRS simulants corresponding to five real-waste tanks. Chemical analyses of the tanks provided the concentrations of sodium, potassium, cesium, nitrate, and free hydroxide. ${ }^{1}$ When preparing the simulants, the total concentration of cations could be as high as $5.6 \mathrm{M}$. The nitrate and hydroxide concentrations measured in the tanks could not balance the cation concentration. The quantity of anion still not accounted for by these analyses was filled either with chloride or with nitrite anions. Based on the total composition of the SRS waste, these four anions and three cations were determined to be the main components. The model will include species of these ions, and corresponding formation constants will be determined by the sequential modeling of simple systems containing first one cation and one anion at the same time, then systematically increasing the number of components. A model representing the extraction of cesium from different media will then be established and cesium extraction behavior could be predicted by a simple input of the concentrations in the aqueous phase before extraction. 


\section{EXPERIMENTAL PROGRAM}

\subsection{MATERIALS}

Stock solutions of $\mathrm{HNO}_{3}, \mathrm{NaNO}_{3}, \mathrm{NaNO}_{2}, \mathrm{NaCl}$, and $\mathrm{NaOH}$ were prepared and all other concentrations prepared as a dilution of the stock. Sodium hydroxide was diluted from $50 \% \mathrm{wt} / \mathrm{wt}$ received from J. T. Baker, Lot $\mathrm{J} 17045$. All salts were dried at $110^{\circ} \mathrm{C}$ for $>18$ hours and stored in a desiccator prior to solution preparation. Sodium chloride was received from EM Scientific, Lot 33131325; $\mathrm{NaNO}_{2}$ was received as $99.5 \%$ from Aldrich, Lot 07012MS; $\mathrm{NaNO}_{3}$ was received from J. 'T. Baker as reagent grade crystal, Lot M14156. Cesium nitrate was received from Alpha Aesar, $99.9 \%$ and dried prior to use. Potassium nitrate was received from EM Science. Sodium concentrations prepared were $5.6,4.5,2.25,1.00,0.50,0.10$, and $0.01 \mathrm{M} . \mathrm{CsNO}_{3}$ and $\mathrm{KNO}_{3}$ were added at $0.5 \mathrm{mM}$ and $60 \mathrm{mM}$, respectively, directly to the sodium salts, effecting a slight dilution of the initial sodium in solution. Binary salt solutions at anion ratios of $0,0.25,0.50,0.75,0.90$, and 1.0 and total sodium concentration of 4.5 or $5.6 \mathrm{M}$ were also prepared with $\mathrm{CsNO}_{3}$ added at $0.5 \mathrm{mM}$ as well as with and without $\mathrm{KNO}_{3}$ at 60 $\mathrm{mM}$. Potassium extractions from $\mathrm{KNO}_{3}$ solutions at concentrations of $1.0,0.30,0.10,0.01 \mathrm{M}$ were also performed. Measurements of cesium extraction from nitric acid involved pristine solvent that had not been preequilibrated with the corresponding solution of nitric acid without cesium. The organic phase consisted of washed solvent Cs-7SB/ Isopar ${ }^{\circledR}$ L, ORNL Lot\# PVB-B000718-156W (7-28-2000). The radiotracers ${ }^{22} \mathrm{Na}$ and ${ }^{137} \mathrm{Cs}$ were obtained from Isotope Products, Burbank, CA.

\subsection{GENERAL CONTACTING AND COUNTING PROCEDURE}

The capped vials were mounted by clips on a disk that was rotated in a constant-temperature air box at $25.0 \pm 0.5^{\circ} \mathrm{C}$ for 90 minutes. After the contacting period, the vials were centrifuged for 3 minutes at $3600 \mathrm{RPM}$ and $25^{\circ} \mathrm{C}$ in a Sanyo MSE Mistral 2000R temperature-controlled centrifuge. A $300 \mu \mathrm{L}$ aliquot of each phase was subsampled and counted using a Packard Cobra II Auto-Gamma counter. All samples were counted for a period of 10 minutes using a window of $580-750 \mathrm{keV}$.

\subsection{VARIABLE TEMPERATURE EXPERIMENT}

A series of experiments to determine cesium distribution using ${ }^{137} \mathrm{Cs}$ tracer techniques was completed. The distribution of cesium in response to increasing concentrations of $\mathrm{NaOH}$ and $\mathrm{NaNO}_{3}$ at two temperatures, $20^{\circ} \mathrm{C}$ and $35^{\circ} \mathrm{C}$, was examined. Contacting experiments were carried out using an 
$\mathrm{O} / \mathrm{A}$ of unity. All contacts were performed in duplicate. The aqueous phase consisted of $0.5 \mathrm{mM} \mathrm{CsNO}_{3}$ and varied concentrations of either $\mathrm{NaOH}$ or $\mathrm{NaNO}_{3}$ at $0.01,0.1,0.5,1.0,2.25,4.5$, and $5.6 \mathrm{M} .{ }^{137} \mathrm{Cs}$ tracer was introduced at $0.1 \mu \mathrm{Ci} / \mathrm{mL}$ aqueous phase. The series of $0.5 \mathrm{mM} \mathrm{CsNO} 3$ in $\mathrm{NaOH}$ or $\mathrm{NaNO}_{3}$ solutions were prepared by aqueous dilutions. The contacts were carried out for a period of 90 minutes in $5.0 \mathrm{~mL}$ VWR Cat. No. 66008-400 clear polypropylene vials.

The capped vials were mounted by clips on a disk which was rotated in a constant-temperature air box at $20.2 \pm 0.5^{\circ} \mathrm{C}$ for 90 min or on a similar wheel located in a LabLine Imperial III Model $306 \mathrm{M}$ Incubator at $35.8^{\circ} \mathrm{C}$ for the same period of time. After the 90 minute contacting period, the vials were centrifuged for 3 minutes at 3600 RPM and $22^{\circ} \mathrm{C}$ in a Sanyo MSE Mistral 2000R temperature-controlled centrifuge. A $300 \mu \mathrm{L}$ aliquot of each phase was subsampled and counted.

\subsection{EXPERIMENTS WITH CALIXARENE-FREE SOLVENT}

In this experiment cesium extraction as a function of the solvent/modifier/trioctylamine (TOA) system was investigated. A contacting experiment was carried out, using an $\mathrm{O} / \mathrm{A}$ volume ratio of unity, in which $1 \mathrm{~mL}$ of washed calix-free CSSX solvent was contacted at $25^{\circ} \mathrm{C}$ with $1 \mathrm{~mL}$ of an aqueous phase consisting of $0.5 \mathrm{mM} \mathrm{CsNO}_{3}$ and variable concentrations of $\mathrm{NaOH}(0.01,0.1,0.5,1.0,2.25,4.5$, and 5.6 M).

The calix-free organic phase was prepared by adding Cs-7SB modifier (Lot no. B000718-24DM) at $0.5 \mathrm{M}$, and trioctylamine (Lot no. B000718-105L) at 0.001M to Isopar(B) L (Lot no. 0306-10967). This solvent was then washed in Teflon® FEP labware using an O/A volume ratio of unity, twice with $0.1 \mathrm{M}$ $\mathrm{NaOH}$ and $50 \mathrm{mM} \mathrm{HNO}_{3}$, and three times with DDI water. The aqueous phases were made by appropriately diluting a $5.6 \mathrm{M}$ working stock of $\mathrm{NaOH}$ and a $50 \mathrm{mM}$ solution of $\mathrm{CsNO}_{3} \cdot{ }^{137} \mathrm{Cs}$ tracer was introduced at $0.1 \mu \mathrm{Ci} / \mathrm{mL}$ aqueous phase. The contacts were carried out for a period of 90 minutes in 5.0 mL VWR Cat. No. $66008-400$ clear polypropylene vials.

\subsection{ION-CHROMATOGRAPHY EXPERIMENTS}

The solvent (Lot B000718-156W) was contacted with an equal volume of the appropriate salt solution in $2 \mathrm{~mL}$ polypropylene vials for 1 hour by rotation in a thermostated air box set at $25 \pm 0.1^{\circ} \mathrm{C}$. All samples were centrifuged for 3 minutes at $3500 \mathrm{rpm}$ to confirm complete phase disengagement. The organic phase was then contacted with a five to ten-fold volume of dilute $\mathrm{HNO}_{3}(1 \mathrm{mM})$ to strip the metal ions into the aqueous phase. Results were based on the first strip since the metal recovery was equal or greater than $98 \%$. The strip solutions were analyzed with a Dionex Model DX500 equipped with a GP40 
pump and a CD20 conductivity detector. The cations sodium, potassium and cesium were separated and analyzed using a CS12A analytical column coupled with a CG12A guard column. The analysis used 20 $\mathrm{mM} \mathrm{H}_{2} \mathrm{SO}_{4}$ eluent at $1 \mathrm{~mL} / \mathrm{min}$ in an isocratic run of 20 minutes. Background conductivity was $0.2 \mu \mathrm{S}$ using CSRS-Ultra suppressor in auto-regeneration mode set at $300 \mathrm{~mA}$. A five-level external standardization for each metal, Na, K, and Cs, was used. Duplicates were run for each sample and were analyzed with $\pm 2 \%$ error. 


\section{PROGRAM SXFIT}

\subsection{DESCRIPTION OF THE PROGRAM}

The program SXFIT is a program that can model thermodynamics data based on the constituents of the systems and the species that are being formed. Although the program's ability to model different kinds of systems is almost limitless, we will describe its capability to handle distribution ratios of ions, since our interest here is to be able to predict cesium extraction behavior. Like the preceding codes $\mathrm{SXLSQ}^{2}, \mathrm{SXLSQA}^{3}$, and SXLSQI ${ }^{4}, \mathrm{SXFIT}^{5}$ is a program written in FORTRAN that refines a series of given inputs based on the least-squares minimization of the difference between the observed and the calculated quantities. The main improvement of SXFIT over predecessor codes is the fact that an unlimited number of constituents can be input. The program then calls for the parameters that are used to calculate the activity effects occurring in the aqueous phase (Masson and Pitzer coefficients) and the organic phase (Solubility parameters). In addition, molecular weights and non-aqueous molar volumes of the different constituents need to be provided along with the dielectric constant and the solubility parameter of the diluent in the organic phase. All initial concentrations of constituents are entered in a data file. Finally, based on the knowledge of the extraction reactions that occur during the process, a few reasonable species (products of the extraction system) may also be supplied with their formation constants. The program then calculates all concentrations of all constituents at equilibrium and the distribution coefficients of the ion of interest. Depending on the differences between the observed and calculated values, the program will then adjust the formation constants of the input species until the best fit is obtained. Of course, this could easily become a simple curve-fitting exercise in which a large number of parameters are used to fit a smaller number of data points. However, the user must ensure that all the species and their relative formation constants are chemically reasonable. Usually, the preference will be given to a model that contains the lowest number of species for a given goodness of fit, represented in the program by the agreement factor. A perfect fit with an accurate experimental error on all the data points yields an agreement factor of 1 . A value greater than 1 indicates a poorer fit or an underestimate of the experimental error, while a value between 0 and 1 indicates an overestimate of the experimental error. 


\subsection{ASSUMPTIONS}

The solvent used in this system comprises $0.01 \mathrm{M}$ Calix[4]arene-bis(tert-octylbenzo crown-6) (BOBCalixC6), $0.5 \mathrm{M}$ 1-(2,2,3,3-tetrafluoropropoxy)-3-(4-sec-butylphenoxy)-2-propanol (Cs7-SB modifier), and $0.001 \mathrm{M}$ trioctylamine (TOA) in Isopar® L. The concentrations of the modifier and of TOA are held constant. The concentration of the modifier is large enough to neglect the amount that is being complexed during the extraction of the cations. Therefore, it will not appear in any species of the model. Regarding TOA, we chose not to include it in the model. Its only influence occurs when the aqueous phase contains enough acid to convert TOA into its acidic form, which in turn increases the amount of nitrate in the organic phase. In this work, only two sets of data involved nitric acid, and it was found that TOA did not have any influence on the cesium or potassium distribution ratios. In future modeling, this restriction will need to be lifted to properly account for acid balance in scrubbing and stripping. Likewise, an accurate accounting of volume and concentration changes would benefit from knowledge of water transferred to and from the solvent; this was omitted from the present treatment.

\subsection{PARAMETERS USED}

The program requires a series of input parameters, most of which are available in published handbooks and literature. Those parameters involved in the activity coefficients in the organic and aqueous phases can be refined by the program (Pitzer parameters, solubility parameters). However, for present purposes, the parameters were either calculated prior to any modeling or obtained from referenced sources and kept constant. The only parameters refined during the modeling process itself were the formation constants of the species in the organic phase. 
Table 1. Molecular weights and non aqueous molar volumes of the constituents

\begin{tabular}{l|c|c}
\hline Constituent & Molecular Weight (g/mol) & $\begin{array}{c}\text { Non aqueous molar volume } \\
\left(\mathbf{c m}^{3} / \mathbf{m o l}\right)^{*}\end{array}$ \\
\hline $\mathrm{Na}^{+}$ & 22.990 & 10 \\
$\mathrm{~K}^{+}$ & 39.098 & 9 \\
$\mathrm{Cs}^{+}$ & 132.91 & 21.5 \\
$\mathrm{H}^{+}$ & 1.008 & 0 \\
$\mathrm{NO}_{3}^{-}$ & 62.005 & 29 \\
$\mathrm{Cl}^{-}$ & 35.450 & 18 \\
$\mathrm{NO}_{2}^{-}$ & 46.006 & 26 \\
$\mathrm{OH}^{-}$ & 17.008 & 18 \\
$\mathrm{BOBCalixC6}^{-}$ & 1149.53 & 500 \\
Diluent (Isopar( L) & 170 & 227 \\
Water & & 18 \\
\hline
\end{tabular}

*The values for the ions are based on their aqueous molar volumes $\mathrm{V}_{0}$ presented in Table 2 . The value for sodium is a personal communication from Charles F. Baes, Jr.

The values for the constituents presented in Table 1 are those called by the program and changeable by the users. The molecular weight of water is $18.015 \mathrm{~g} / \mathrm{mol}$. This value is a constant and non-changeable.

Table 2. Masson coefficients ${ }^{6}$ of ions present in the system.

\begin{tabular}{l|c|c}
\hline Constituent & $\mathbf{V}_{\mathbf{0}}$ & $\mathrm{Sv}$ \\
\hline $\mathrm{Na}^{+}$ & -1.5 & 1.89 \\
$\mathrm{~K}^{+}$ & 8.73 & 1.10 \\
$\mathrm{Cs}^{+}$ & 21.40 & 1.29 \\
$\mathrm{H}^{+}$ & 0 & 0 \\
$\mathrm{NO}_{3}^{-}$ & 29.33 & 0.543 \\
$\mathrm{Cl}^{-}$ & 18.12 & 0.83 \\
$\mathrm{NO}_{2}^{-}$ & 26.5 & 2.00 \\
$\mathrm{OH}^{-}$ & -1.04 & 2.32 \\
\hline
\end{tabular}


Table 3. Pitzer parameters ${ }^{7}$ for the interactions between ions present in the system.

\begin{tabular}{l||c|c|c}
\hline Interaction & \multicolumn{1}{|c|}{$\beta_{0}$} & $\beta_{1}$ & $\mathrm{C}_{\Phi}$ \\
\hline $\mathrm{H}^{+}-\mathrm{NO}_{3}^{-}$ & 0.11190 & 0.36860 & 0.002470 \\
$\mathrm{Na}^{+}-\mathrm{NO}_{3}^{-}$ & 0.06800 & 0.01783 & -0.000720 \\
$\mathrm{Na}^{+}-\mathrm{Cl}^{-}$ & 0.07650 & 0.26640 & 0.001270 \\
$\mathrm{Na}^{+}-\mathrm{NO}_{2}^{-}$ & 0.06410 & 0.10150 & -0.004900 \\
$\mathrm{Na}^{+}-\mathrm{OH}^{-}$ & 0.08640 & 0.25300 & 0.004000 \\
$\mathrm{~K}^{+}-\mathrm{NO}_{3}^{-}$ & -0.08160 & 0.04940 & 0.006600 \\
$\mathrm{~K}^{+}-\mathrm{Cl}^{-}$ & 0.04835 & 0.21220 & -0.000840 \\
$\mathrm{~K}^{+}-\mathrm{NO}_{2}^{-}$ & 0.01510 & 0.01500 & 0.000700 \\
$\mathrm{~K}^{+}-\mathrm{OH}^{-}$ & 0.12980 & 0.32000 & 0.000410 \\
$\mathrm{Cs}^{+}-\mathrm{NO}_{3}^{-}$ & -0.07580 & -0.06690 & 0.000000 \\
$\mathrm{Cs}^{+}-\mathrm{Cl}^{-}$ & 0.03478 & 0.03974 & -0.000496 \\
$\mathrm{Cs}^{+}-\mathrm{NO}_{2}^{-}$ & 0.04270 & 0.06000 & -0.005100 \\
$\mathrm{Cs}^{+}-\mathrm{OH}^{-}$ & 0.15000 & 0.30000 & 0.000000 \\
\hline
\end{tabular}

All $\beta_{2}$ values are set to 0 . Parameter $\alpha_{1}=2$, and $\alpha_{2}=0$, since all the interactions are between two monocharged ions.

Regarding the activity coefficients in the organic phase, all the product species were assigned a similar value. The solubility parameter of the diluent (Isopar® L) and the extractant BOBCalixC6 were determined by group contribution calculations ${ }^{8}$ A best estimate of the values of the product species was made. They were kept constant as no reliable source for better values is available. In addition, the solubility parameters usually do not have a major impact on the determination of the product species formation constants. They avoid assuming ideality in the organic phase, but do not have a crucial effect on the final results, as the mole fraction of extracted species in the solvent is very small. The dielectric constant of the diluent equals 2.014; its solubility parameter is set to $18.40 \mathrm{~J}^{1 / 2} \mathrm{~cm}^{-3 / 2}$. The solubility parameter of water is set to $51.13 \mathrm{~J}^{1 / 2} \mathrm{~cm}^{-3 / 2}$.

The calixarene solubility parameter was estimated with the group contributions and determined to be $21 \mathrm{~J}^{1 / 2} \mathrm{~cm}^{-3 / 2}$. All organic species formed in the organic phase were assigned a solubility parameter of $19.8 \mathrm{~J}^{1 / 2} \mathrm{~cm}^{-3 / 2}$, which is also the solubility parameter of the modifier. Previous studies showed that at least one molecule of modifier was included in the complexes, and the solubility parameter is close enough to the value for the calixarene to avoid any major activity effect. 


\section{RESULTS AND DISCUSSION}

Tables with all experimental results used in this modeling can be found in the appendix. By way of brief explanation, we include here a description of the approach chosen to find the best model. The method used to model the first set of data is discussed in detail. Fewer details will be given for subsequent groups, as the modeling technique and approach remain the same.

\subsection{EXTRACTION MODELING FROM NITRATE MEDIA}

The first step was to model data that involved only one anion. Indeed, all the other sodium salts were spiked with potassium nitrate and/or cesium nitrate, and the corresponding amount of anion, however small, was taken into account.

Data on cesium extraction from cesium nitrate and nitric acid yielded the formation constants of $\mathrm{CsNO}_{3}$ Calix (o) and $\left(\mathrm{CsNO}_{3}\right)_{2} \mathrm{Calix}(\mathrm{o})$; the notation (o) refers to the organic phase. Addition of data on potassium extraction from potassium nitrate alone or mixed with cesium nitrate yielded the formation constant of $\mathrm{KNO}_{3} \mathrm{Calix}(\mathrm{o})$. Finally, addition of data on potassium and cesium extraction from sodium nitrate allowed us to calculate the formation constant of $\mathrm{NaNO}_{3} \mathrm{Calix}(\mathrm{o})$.

Table 4. Species and formation constants for the model derived for nitrate data

\begin{tabular}{lc}
\hline Species & Formation constant \\
\hline $\mathrm{CsNO}_{3} \mathrm{Calix}(\mathrm{o})$ & $\log _{10} \mathrm{~K}=3.615$ \\
$\left(\mathrm{CsNO}_{3}\right)_{2} \mathrm{Calix}(\mathrm{o})$ & $\log _{10} \mathrm{~K}=4.317$ \\
$\mathrm{KNO}_{3}$ Calix(o) & $\log _{10} \mathrm{~K}=1.387$ \\
$\mathrm{NaNO}_{3}$ Calix(o) & $\log _{10} \mathrm{~K}=-0.943$ \\
\hline
\end{tabular}

The fit of all the data is presented in Figures 1 and 2 . The overall agreement factor is 2.7 , with an assumption of a uniform $5 \%$ error on all the data points. 


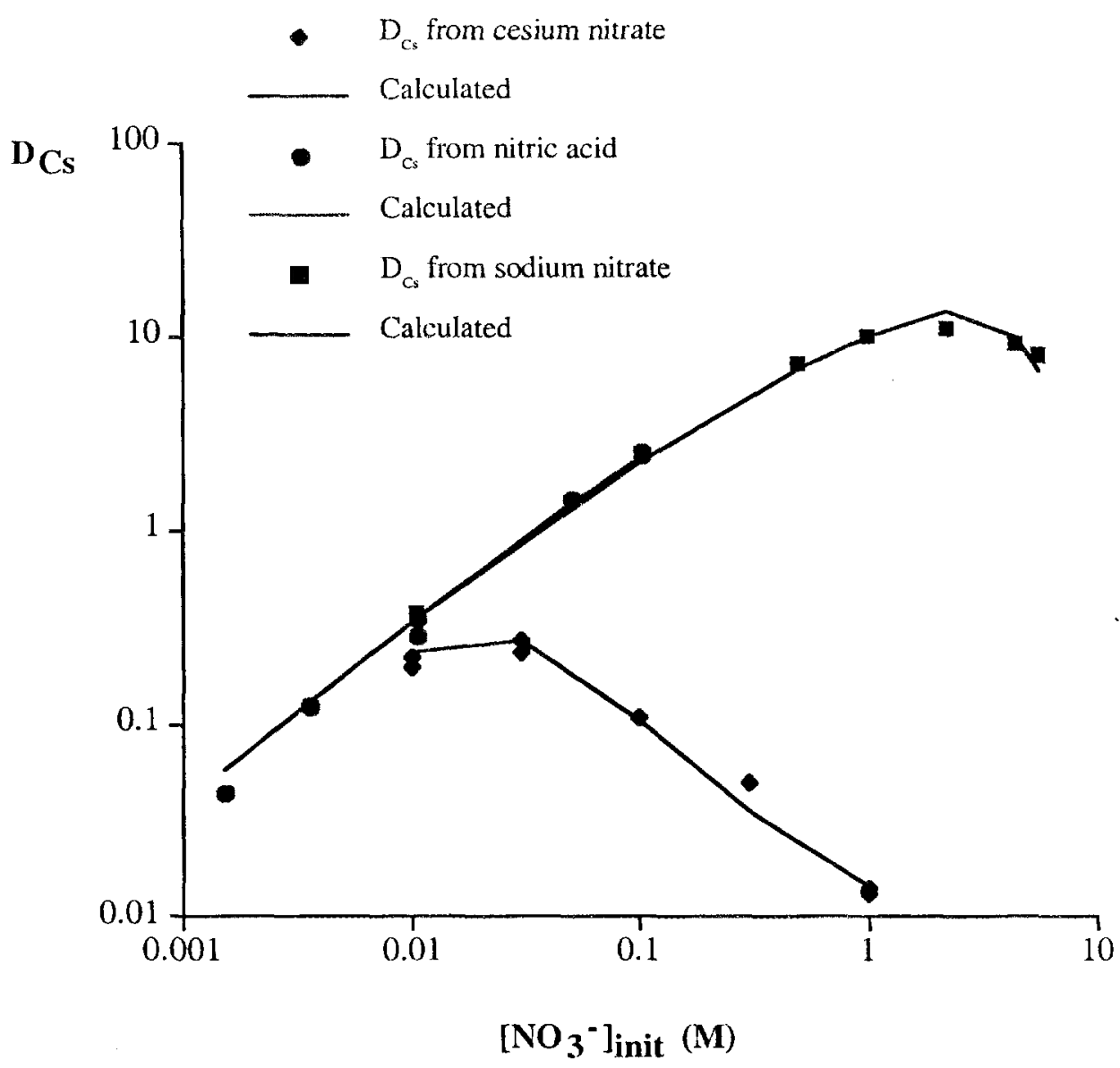

Fig. 1. Fit of cesium distribution ratios for nitrate media

A few comments need to be made regarding the dependence of cesium extraction with the nitrate concentration. A slope of 1 is expected when a complex involving an ion-paired cesium nitrate species is the major product formed in the organic phase.

$$
\mathrm{Cs}^{+}+\mathrm{NO}_{3}^{-}+\text {BOBCalixC6(o) } \longleftrightarrow \mathrm{CsNO}_{3}(\mathrm{BOBCalix})(\mathrm{o})
$$

This is well-demonstrated with the nitric acid experiment. The other two depart from the previous statement as the calixarene is loaded when cesium is extracted from increasing concentrations of cesium nitrate. A similar phenomenon is observed when reaching high concentrations of sodium nitrate where loading and activity effects give a trend that shows the cesium distribution ratios reach a maximum and then decrease. 


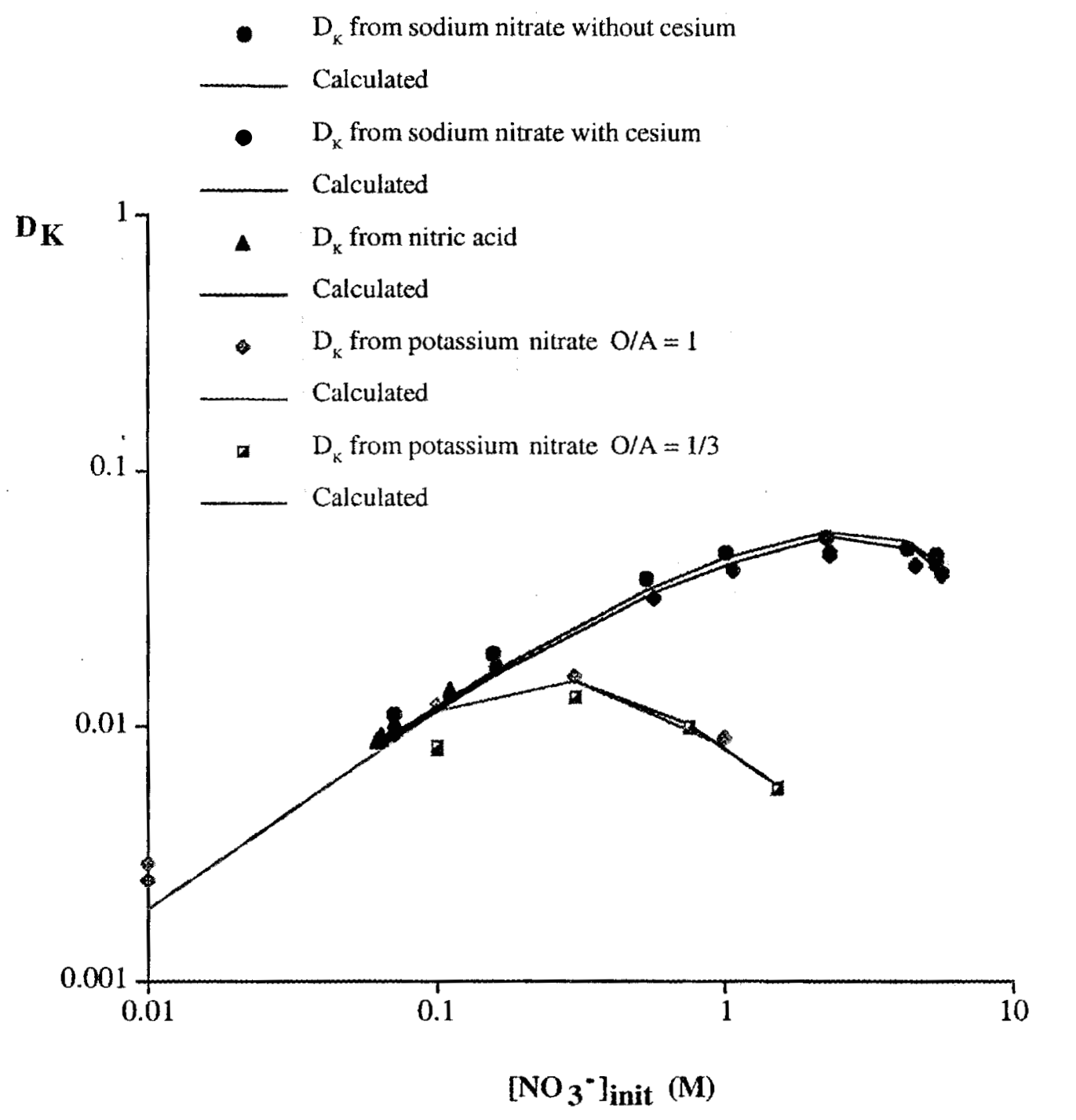

Fig. 2 Fit of potassium distribution ratios for nitrate media

Similar conclusions can be drawn from the potassium extraction experiment. Potassium is extracted much less than cesium, but its initial concentration in sodium nitrate or nitric acid is about 100 times greater than cesium under similar conditions. The same trend of loading effects appears here, too.

\subsection{EXTRACTION MODELING FROM HYDROXIDE MEDIA}

The second set of data involves the fitting of cation extraction from sodium hydroxide. The results found previously for the nitrate system are required since all the potassium and the cesium were added as 
spikes of nitrate solutions. Preliminary results on sodium extraction showed that the presence of calixarene was not required to extract this cation, as the amount of sodium present in the organic phase was the same whether or not the calixarene was present in the solvent.

The species listed Table 5 were added to the model to achieve a fit of data obtained in hydroxide systems. Figure 3 summarizes the fit as a function of hydroxide concentration.

Table 5. Species and formation constants for the model derived for hydroxide data

\begin{tabular}{lc}
\hline Species & Formation constant \\
\hline CsOH(o) & $\log _{10} \mathrm{~K}=-2.264$ \\
CsOHCalix(o) & $\log _{10} \mathrm{~K}=3.332$ \\
$\mathrm{KOHCalix}(\mathrm{o})$ & $\log _{10} \mathrm{~K}=1.549$ \\
$\mathrm{NaOH}(\mathrm{o})$ & $\log _{10} \mathrm{~K}=-0.565$ \\
\hline
\end{tabular}




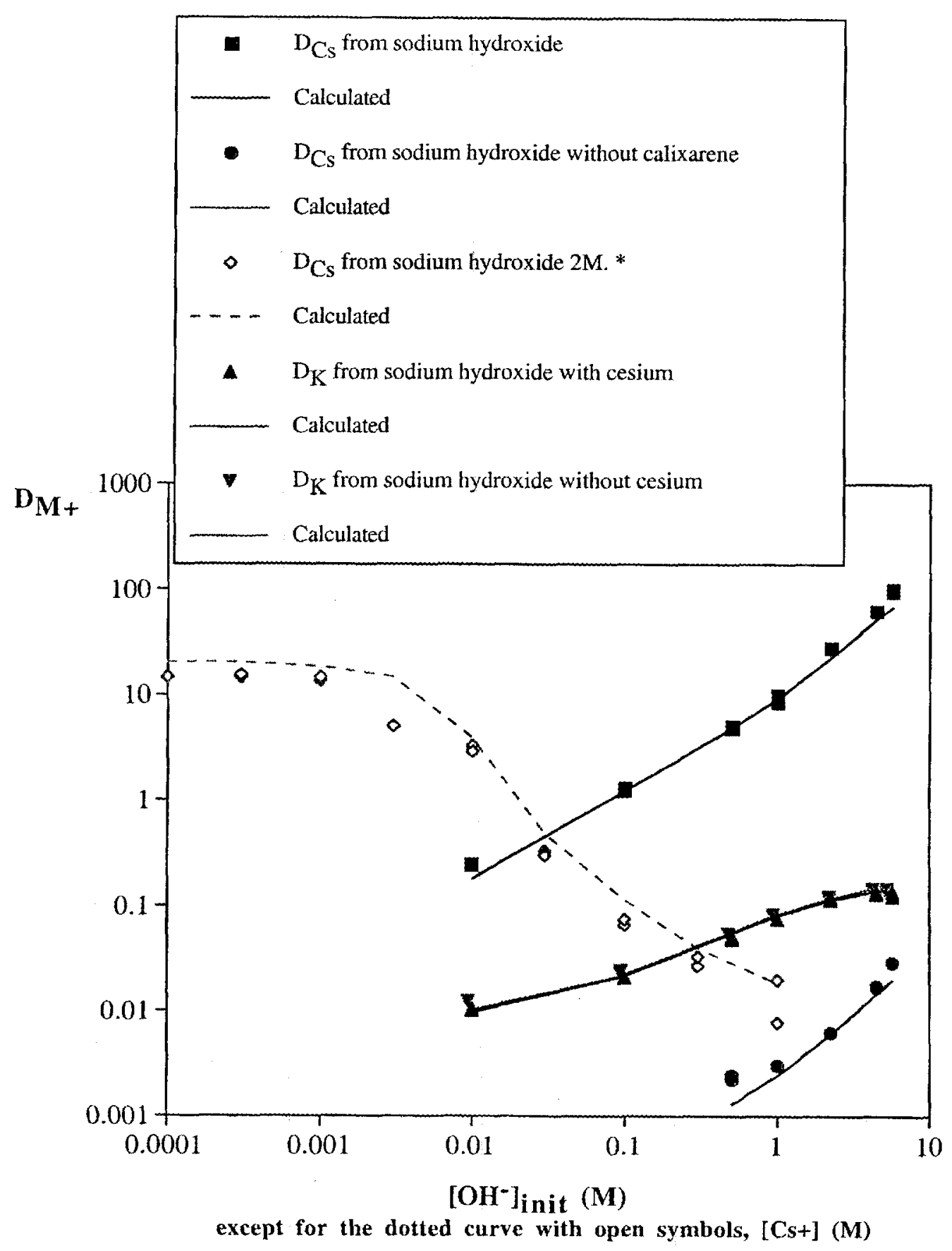

Fig. 3. Fit of data points for hydroxide media

The fit for all the data is rather good with the exception of the curve for which the concentration of sodium hydroxide was held constant and the concentration of cesium nitrate varied (* dotted curve and open symbols = variable cesium nitrate concentration in $\mathrm{NaOH} 2 \mathrm{M}$ ). The reliability of these results was rather low since a third phase was observed for most of them. However, the results and the corresponding fit are presented to show that the overall trend is followed. Consider also, when a third phase is observed, 
the distribution coefficients are usually lower than they would be without a third phase since some of the activity present in the organic phase that is subsampled for counting is present in the third phase. This is exactly what is observed in this case.

\subsection{EXTRACTION MODELING FROM NITRITE OR CHLORIDE MEDIA}

The inclusion of the data points containing nitrite salts led to the introduction of three more species in the model:

Table 6. Species and formation constants for the model derived for nitrite data

\begin{tabular}{lc}
\hline Species & Formation constant \\
\hline $\mathrm{CsNO}_{2}$ Calix(o) & $\log _{10} \mathrm{~K}=3.152$ \\
$\mathrm{KNO}_{2}$ Calix(o) & $\log _{10} \mathrm{~K}=1.098$ \\
$\mathrm{NaNO}_{2}$ Calix(o) & $\log _{10} \mathrm{~K}=-1.313$ \\
\hline
\end{tabular}

Among the anions in the study, chloride has the highest hydration energy, and therefore is not as extractable as the other three. The formation constants of the species involving this anion are expected to be lower than those found earlier. Extraction tests showed that sodium chloride is not extracted detectably when the calixarene is absent. The inclusion of the data points containing chloride salts led to comparable species:

Table 7. Species and formation constants for the model derived for chloride data

\begin{tabular}{lc}
\hline Species & Formation constant \\
\hline CsClCalix(o) & $\log _{10} \mathrm{~K}=2.587$ \\
$\operatorname{KClCalix}(0)$ & $\log _{10} \mathrm{~K}=0.575$ \\
$\mathrm{NaClCalix}(0)$ & $\log _{10} \mathrm{~K}=-1.455$ \\
\hline
\end{tabular}

Figures 4 and 5 present the fit obtained with the model for the systems containing chloride and nitrite, respectively. 


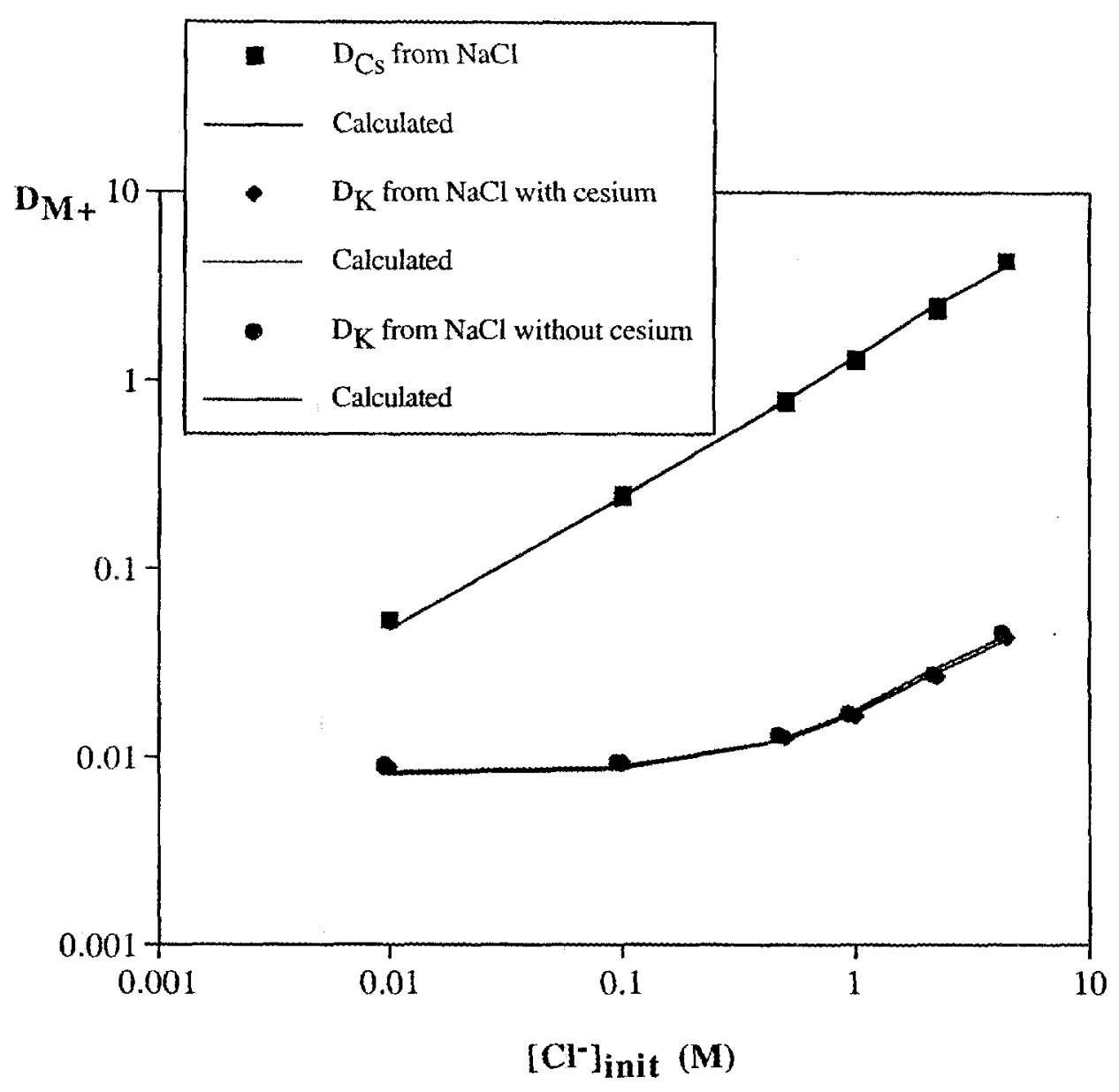

Fig. 4. Fit of cesium and potassium distribution ratios for chloride media 


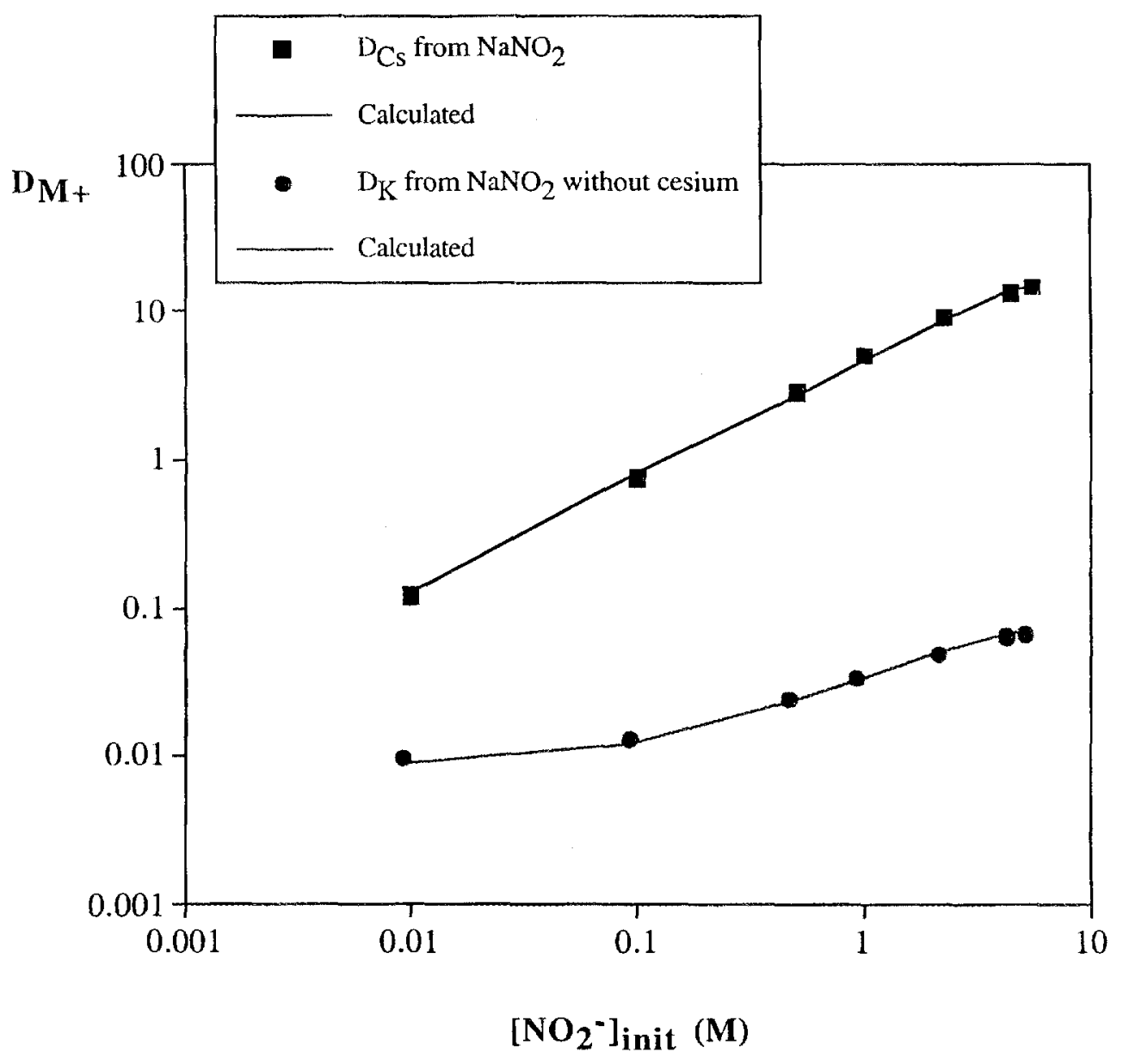

Fig. 5 Fit of cesium and potassium distribution ratios for nitrite media

These experiments conclude our tests from simple systems to determine the best model at $25{ }^{\circ} \mathrm{C}$. The subsequent experiments attempted to validate the findings with more complicated systems.

\subsection{VARIABLE TEMPERATURE TESTS}

Two sets of experiments (extraction of cesium from sodium nitrate or sodium hydroxide) were carried out a two temperatures, $20^{\circ} \mathrm{C}$ and $35^{\circ} \mathrm{C}$. It is shown that lower distribution ratios are obtained for higher temperatures, which agrees with the exothermic character of the extraction reaction.

The modeling of these data involved only the determination of the formation constants. Although the activity coefficients are also temperature dependent, the values for $25^{\circ} \mathrm{C}$ were also used at $20^{\circ} \mathrm{C}$ and $35^{\circ} \mathrm{C}$, since the change is small. Formation constants are mentioned for information purposes only. All 
experiments carried out at $25^{\circ} \mathrm{C}$ that allowed the determination of the model to this point would have been needed at other temperatures to determine an accurate model at these temperatures.

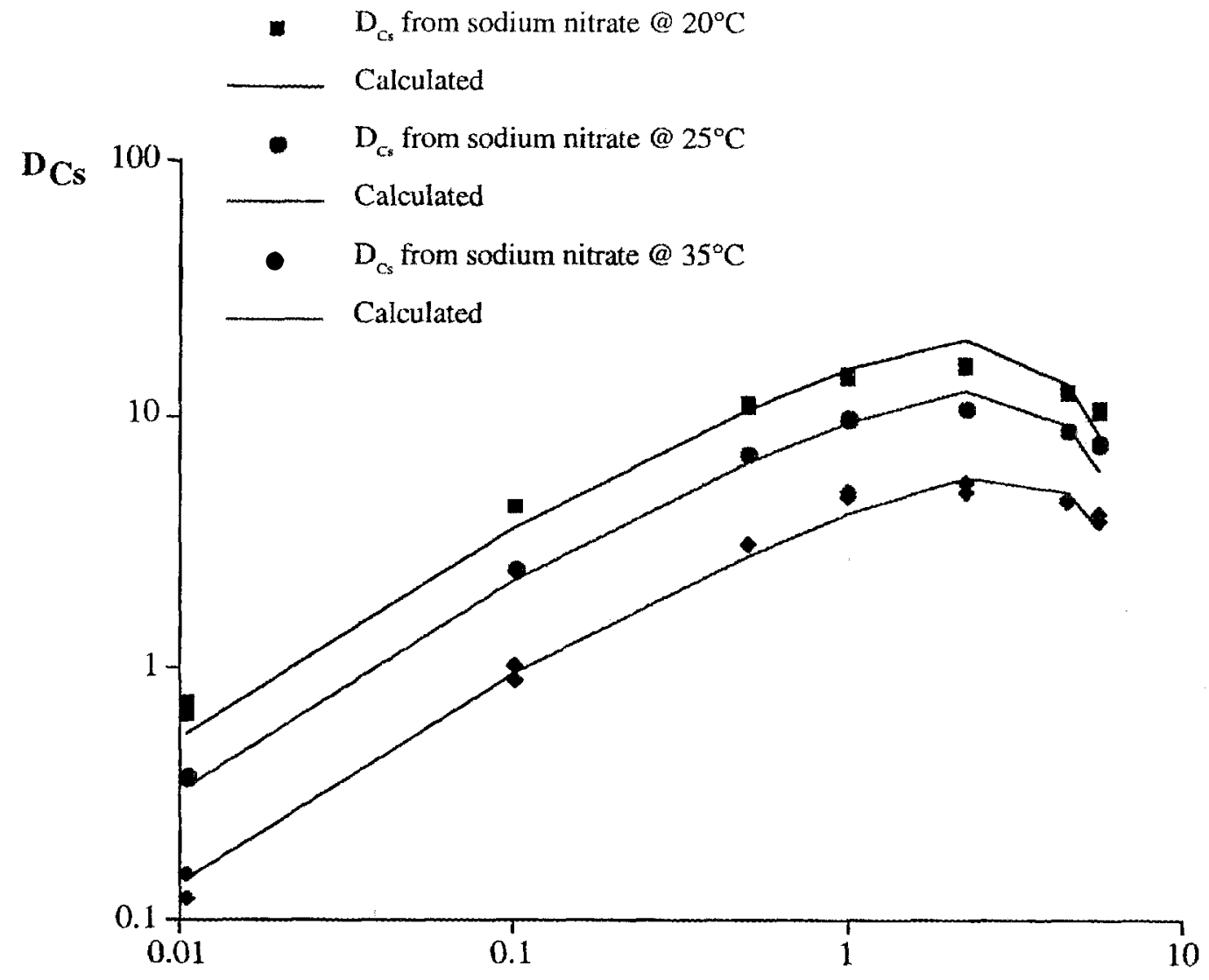

$\left[\mathrm{NO}_{3}{ }^{-}\right]_{\text {init }}(\mathrm{M})$

Fig. 6. Fit of cesium distribution ratios for nitrate media at different temperature

Table 8. Formation constant for the model including nitrate data at different temperatures

\begin{tabular}{lccc}
\hline Species & Formation constant & Formation constant & Formation constant \\
& $@ 20^{\circ} \mathrm{C}$ & $@ 25^{\circ} \mathrm{C}$ & $@ 35^{\circ} \mathrm{C}$ \\
\hline $\mathrm{CsNO}_{3} \mathrm{Calix}(\mathrm{o})$ & $\log _{10} \mathrm{~K}=3.831$ & $\log _{10} \mathrm{~K}=3.615$ & $\log _{10} \mathrm{~K}=3.251$ \\
$\left(\mathrm{CsNO}_{3}\right)_{2} \mathrm{Calix}(\mathrm{o})$ & kept constant & $\log _{10} \mathrm{~K}=4.317$ & kept constant \\
$\mathrm{NaNO}_{3} \mathrm{Calix}(\mathrm{o})$ & $\log _{10} \mathrm{~K}=-0.851$ & $\log _{10} \mathrm{~K}=-0.943$ & $\log _{10} \mathrm{~K}=-1.152$ \\
\hline
\end{tabular}


The formation constant of the complex involving two cesium ions is held constant for the three temperatures since there are almost no data points supporting this species in the data sets collected at 20 ${ }^{\circ} \mathrm{C}$ or $35^{\circ} \mathrm{C}$. Formation constants of complexes containing cesium and sodium nitrate (Table 8) and cesium hydroxide (Table 9) were included in these models for the corresponding temperatures. Figures 6 and 7 present the fit obtained as a function of nitrate and hydroxide concentrations, respectively, at the different temperatures. The expected trend of the formation constant values follow very well the exothermic behavior observed for this system. The fit could be improved, particularly for the data at 35 ${ }^{\circ} \mathrm{C}$, which suggests that some of the assumptions are not valid and the appropriate data sets need to be collected to reduce the uncertainties.

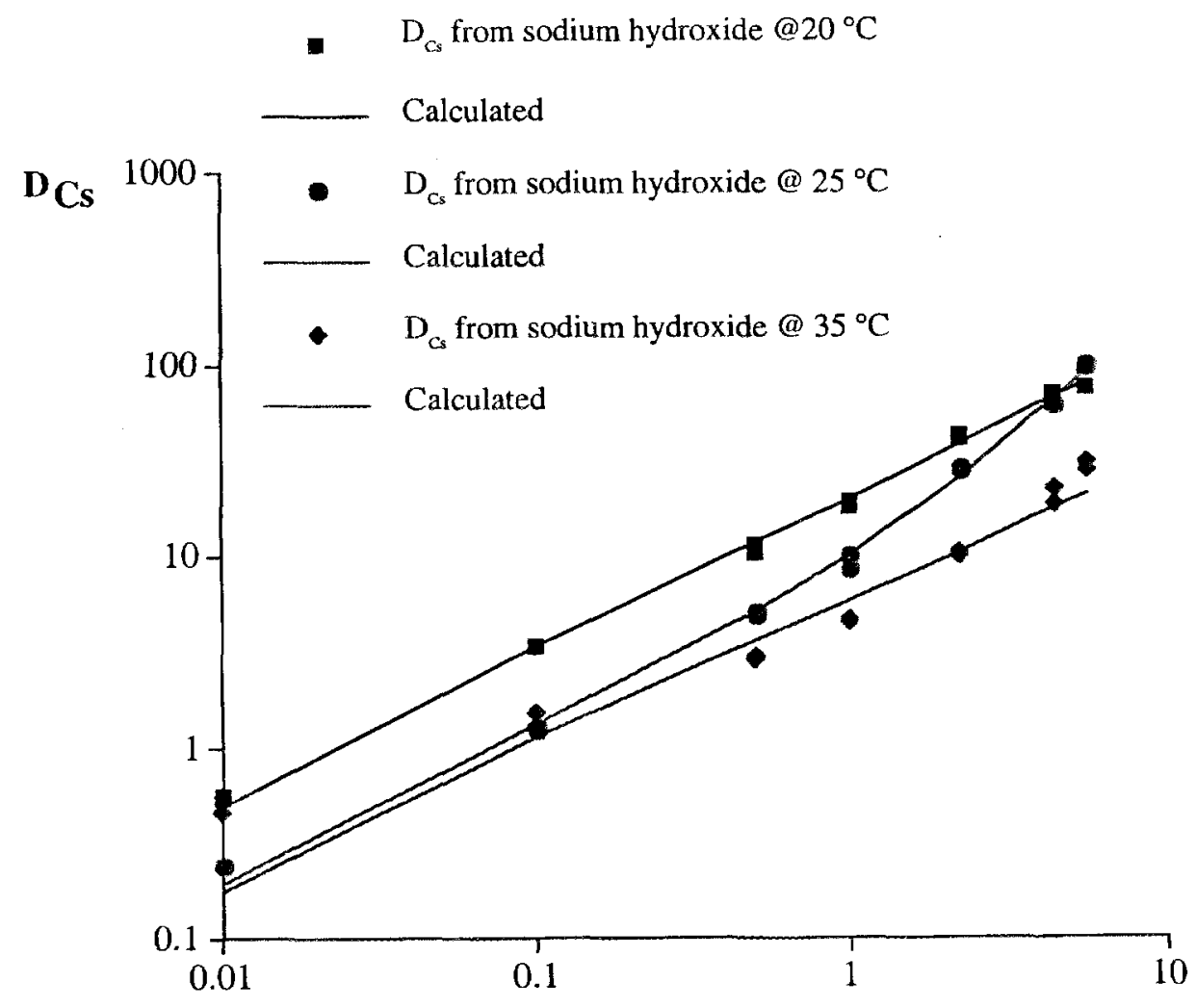

$\left[\mathrm{OH}^{-}\right]_{\text {init }}(\mathrm{M})$

Fig. 7. Fit of cesium distribution ratios for hydroxide media at different temperature 
Table 9. Formation constant for the model including hydroxide data at different temperatures

\begin{tabular}{lccc}
\hline Species & Formation constant & Formation constant & Formation constant \\
& $@ 20^{\circ} \mathrm{C}$ & $@ 25^{\circ} \mathbf{C}$ & $@ 35{ }^{\circ} \mathrm{C}$ \\
\hline CsOHCalix $(0)$ & $\log _{10} \mathrm{~K}=3.531$ & $\log _{10} \mathrm{~K}=3.332$ & $\log _{10} \mathrm{~K}=3.008$ \\
\hline
\end{tabular}

\subsection{TESTS INVOLVING TANK SIMULANTS}

Real waste batch tests conducted at the Savannah River Site provided the concentrations of major components (sodium, potassium, cesium, hydroxide, and nitrate) of the waste. ${ }^{1}$ From these results, simulants were prepared using either nitrite or chloride. These initial concentrations were entered into a data file, and the program SXFIT predicted the cesium distribution ratio based on all the species and formation constants presented above. Table 10 presents the comparison between the measured distribution ratios and those that were predicted. The O/A volume ratios were all 1/3. All experiments were carried out at $25^{\circ} \mathrm{C}$.

Table 10. Comparison of measured and predicted distribution ratios for tank simulants

\begin{tabular}{|c|c|c|c|c|}
\hline Tank & Composition & $\mathbf{D}_{\mathrm{Cs}}$ measured & $\mathbf{D}_{C_{S}}$ predicted & error \\
\hline \multirow{6}{*}{ Tank 13} & {$[\mathrm{Na}+]=5.6 \mathrm{M}$} & \multirow{6}{*}{8.38} & \multirow{6}{*}{9.75} & \multirow{6}{*}{$16.3 \%$} \\
\hline & {$\left[\mathrm{K}^{+}\right]=0.067 \mathrm{M}$} & & & \\
\hline & {$\left[\mathrm{Cs}^{+}\right]=0.512 \mathrm{mM}$} & & & \\
\hline & {$\left[\mathrm{OH}^{-}\right]=2.29 \mathrm{M}$} & & & \\
\hline & {$\left[\mathrm{NO}_{3}{ }^{\circ}\right]=0.767 \mathrm{M}$} & & & \\
\hline & {$\left[\mathrm{NO}_{2}^{-}\right]=2.6 \mathrm{M}$} & & & \\
\hline \multirow{6}{*}{$\begin{array}{l}\text { Tank } 13 \\
\text { (with chloride, } \\
\text { substituted for nitrite) }\end{array}$} & {$[\mathrm{Na}+]=5.6 \mathrm{M}$} & \multirow{6}{*}{6.68} & \multirow{6}{*}{6.88} & \multirow{6}{*}{$3.0 \%$} \\
\hline & {$\left[\mathrm{K}^{+}\right]=0.067 \mathrm{M}$} & & & \\
\hline & {$\left[\mathrm{Cs}^{+}\right]=0.512 \mathrm{mM}$} & & & \\
\hline & {$\left[\mathrm{OH}^{-}\right]=2.29 \mathrm{M}$} & & & \\
\hline & {$\left[\mathrm{NO}_{3}{ }^{-}\right]=0.767 \mathrm{M}$} & & & \\
\hline & {$\left[\mathrm{Cl}^{-}\right]=2.6 \mathrm{M}$} & & & \\
\hline \multirow{6}{*}{ Tank 26} & {$[\mathrm{Na}+]=5.6 \mathrm{M}$} & \multirow{6}{*}{16.8} & \multirow{6}{*}{15.0} & \multirow{6}{*}{$10.7 \%$} \\
\hline & {$\left[\mathrm{K}^{+}\right]=0.041 \mathrm{M}$} & & & \\
\hline & {$\left[\mathrm{Cs}^{+}\right]=0.219 \mathrm{mM}$} & & & \\
\hline & {$\left[\mathrm{OH}^{-}\right]=4.71 \mathrm{M}$} & & & \\
\hline & {$\left[\mathrm{NO}_{3}{ }^{-}\right]=0.956 \mathrm{M}$} & & & \\
\hline & {$\left[\mathrm{NO}_{2}^{-}\right]=0 \mathrm{M}$} & & & \\
\hline
\end{tabular}




\begin{tabular}{|c|c|c|c|c|}
\hline Tank & Composition & $\mathbf{D}_{\mathrm{Cs}}$ measured & $\mathbf{D}_{\mathrm{Cs}}$ predicted & error \\
\hline \multirow{6}{*}{ Tank 33} & {$[\mathrm{Na}+]=3.3 \mathrm{M}$} & \multirow{6}{*}{16.3} & \multirow{6}{*}{20.5} & \multirow{6}{*}{$25.7 \%$} \\
\hline & {$\left[\mathrm{K}^{+}\right]=5 \mathrm{mM}$} & & & \\
\hline & {$\left[\mathrm{Cs}^{+}\right]=8.03 \mu \mathrm{M}$} & & & \\
\hline & {$\left[\mathrm{OH}^{-}\right]=1.47 \mathrm{M}$} & & & \\
\hline & {$\left[\mathrm{NO}_{3}^{-}\right]=1.44 \mathrm{M}$} & & & \\
\hline & {$\left[\mathrm{NO}_{2}^{-}\right]=0.4 \mathrm{M}$} & & & \\
\hline \multirow{6}{*}{ Tank 35} & {$[\mathrm{Na}+]=5.6 \mathrm{M}$} & \multirow{6}{*}{22.8} & \multirow{6}{*}{23.9} & \multirow{6}{*}{$4.6 \%$} \\
\hline & {$\left[\mathrm{K}^{+}\right]=0.01 \mathrm{M}$} & & & \\
\hline & {$\left[\mathrm{Cs}^{+}\right]=0.188 \mathrm{mM}$} & & & \\
\hline & {$\left[\mathrm{OH}^{-}\right]=2.93 \mathrm{M}$} & & & \\
\hline & {$\left[\mathrm{NO}_{3}{ }^{-}\right]=1.4 \mathrm{M}$} & & & \\
\hline & {$\left[\mathrm{NO}_{2}^{-}\right]=1.3 \mathrm{M}$} & & & \\
\hline \multirow{6}{*}{ Tank 46} & {$[\mathrm{Na}+]=5.6 \mathrm{M}$} & \multirow{6}{*}{17.6} & \multirow{6}{*}{17.3} & \multirow{6}{*}{$1.7 \%$} \\
\hline & {$\left[\mathrm{K}^{+}\right]=0.032 \mathrm{M}$} & & & \\
\hline & {$\left[\mathrm{Cs}^{+}\right]=0.378 \mathrm{mM}$} & & & \\
\hline & {$\left[\mathrm{OH}^{-}\right]=3.98 \mathrm{M}$} & & & \\
\hline & {$\left[\mathrm{NO}_{3}^{-}\right]=0.606 \mathrm{M}$} & & & \\
\hline & {$\left[\mathrm{NO}_{2}^{-}\right]=1.0 \mathrm{M}$} & & & \\
\hline \multirow{6}{*}{$\begin{array}{l}\text { Tank } 46 \\
\text { (with chloride } \\
\text { substituted for nitrite) }\end{array}$} & {$[\mathrm{Na}+]=5.6 \mathrm{M}$} & \multirow{6}{*}{15.4} & \multirow{6}{*}{14.8} & \multirow{6}{*}{$3.8 \%$} \\
\hline & {$\left[\mathrm{K}^{+}\right]=0.032 \mathrm{M}$} & & & \\
\hline & {$\left[\mathrm{Cs}^{+}\right]=0.378 \mathrm{mM}$} & & & \\
\hline & {$\left[\mathrm{OH}^{-}\right]=3.98 \mathrm{M}$} & & & \\
\hline & {$\left[\mathrm{NO}_{3}^{-}\right]=0.606 \mathrm{M}$} & & & \\
\hline & {$\left[\mathrm{Cl}^{-}\right]=1.0 \mathrm{M}$} & & & \\
\hline
\end{tabular}

The prediction is very good in all the cases, for any composition of the simulant. The only overestimation occurred for the simulant that contains a lower concentration of sodium. Otherwise, all the predictions are within an average of $7 \%$ of error, which is excellent for a model that contains a minimum number of product species. This comparison validates the model described previously.

\subsection{PREDICTION OF CESIUM EXTRACTION FROM THE FULL SIMULANT}

Simplified tank simulants were prepared fcontaining only those ions assumed to be playing major roles in the systems. Following this assumption, we decided to go further and test our model by creating a data file containing the initial concentrations representing the full simulant. In order to test our model with the full simulant, a "dummy non-extractable" anion $\left(\mathrm{X}^{-}\right)$was introduced to ensure the electroneutrality of the aqueous phase: 


$$
\left[\mathrm{Na}^{+}\right]+\left[\mathrm{K}^{+}\right]+\left[\mathrm{Cs}^{+}\right]=\left[\mathrm{NO}_{3}^{-}\right]+\left[\mathrm{OH}^{-}\right]+\left[\mathrm{NO}_{2}^{-}\right]+\left[\mathrm{Cl}^{-}\right]+\left[\mathrm{X}^{-}\right]
$$

This "dummy" anion is intended to represent all the anions present in the simulant that are not extracted and assumed to play only minor roles in the extraction process. However, they are important from a global ionic strength standpoint.

Under the aqueous initial conditions:

$$
\begin{gathered}
{\left[\mathrm{Na}^{+}\right]=5.6 \mathrm{M},\left[\mathrm{K}^{+}\right]=0.015 \mathrm{M},\left[\mathrm{Cs}^{+}\right]=1.4 \times 10^{-4} \mathrm{M}} \\
{\left[\mathrm{NO}_{3}^{-}\right]=2.03 \mathrm{M},\left[\mathrm{OH}^{-}\right]=2.06 \mathrm{M},\left[\mathrm{NO}_{2}^{-}\right]=0.5 \mathrm{M},\left[\mathrm{Cl}^{-}\right]=0.024 \mathrm{M} \text { and }\left[\mathrm{X}^{-}\right]=\mathbf{1 . 0 0 1 1 4} \mathrm{M}}
\end{gathered}
$$

and the species with their respective formation constants listed in Table 11, the predicted cesium distribution ratio is 16.8 . The average of all cesium distribution ratios obtained in extraction conditions is 16.9. ${ }^{10}$ This comparison allows a still greater confidence in the reliability of the model, and confirms that the anions present in the simulant other than hydroxide, nitrate, nitrite, and chloride do not play a major role.

Table 11. Model used in this work

\begin{tabular}{cc}
\hline Species & Formation constant \\
\hline $\mathrm{CsNO}_{3}$ Calix(o) & $\log _{10} \mathrm{~K}=3.615$ \\
$\left(\mathrm{CsNO}_{3}\right)_{2}$ Calix(o) & $\log _{10} \mathrm{~K}=4.317$ \\
$\mathrm{CsOH}(\mathrm{o})$ & $\log _{10} \mathrm{~K}=-2.263$ \\
$\mathrm{CsOHCalix}(\mathrm{o})$ & $\log _{10} \mathrm{~K}=3.332$ \\
$\mathrm{CsNO}_{2}$ Calix(o) & $\log _{10} \mathrm{~K}=3.152$ \\
$\mathrm{CsClCalix}_{(0)}$ & $\log _{10} \mathrm{~K}=2.587$ \\
$\mathrm{KNO}_{3} \mathrm{Calix}(\mathrm{o})$ & $\log _{10} \mathrm{~K}=1.387$ \\
$\mathrm{KOHCalix}_{(0)}$ & $\log _{10} \mathrm{~K}=1.549$ \\
$\mathrm{KNO}_{2} \mathrm{Calix}(\mathrm{o})$ & $\log _{10} \mathrm{~K}=1.098$ \\
$\mathrm{KClCalix}_{(0)}$ & $\log _{10} \mathrm{~K}=0.575$ \\
$\mathrm{NaOH}_{(0)}$ & $\log _{10} \mathrm{~K}=-0.565$ \\
$\mathrm{NaNO}_{3} \mathrm{Calix}(\mathrm{o})$ & $\log _{10} \mathrm{~K}=-0.943$ \\
$\mathrm{NaNO}_{2} \mathrm{Calix}(\mathrm{o})$ & $\log _{10} \mathrm{~K}=-1.313$ \\
$\mathrm{NaClCalix}(\mathrm{o})$ & $\log _{10} \mathrm{~K}=-1.455$
\end{tabular}




\section{CONCLUSION}

The model gives a very good overall fit for a large number of data points (almost 300) obtained from simple systems. The overall agreement is adequate for such a large data set and the number of species assumed in the organic phase is very small. In addition, all the formation constants are consistent within themselves. They follow the values of the Gibbs energy of partitioning for the four anions. The definitive test to predict the cesium distribution ratios based on initial concentrations is extremely satisfactory. In addition, the prediction of the distribution coefficient obtained with the full simulant is very close to the value obtained experimentally. We can say that not only does the model fit the data very well, but it also includes the cations and anions that play major roles in more complicated mixtures. 


\section{REFERENCES}

[1] R. A. Peterson, Savannah River Technology Center, Aiken, SC, private communication, Nov., 2000.

[2] C.F. Baes, Ir, W.J. McDowell, S.A. Bryan, The Interpretation of Equilibrium Data from Synergistic Solvent Extraction systems, Solv. Extr. Ion Exch., 5, 1-28 (1987)

[3] C.F. Baes, Jr, B.A. Moyer, G.N. Case, F.I. Case, SXLSQA, A Computer Program for Including Both Complex Formation and Activity Effects in the Interpretation of Solvent Extraction Data, Sep. Sci. Technol, 25, 1675-1688 (1990)

[4] C.F. Baes, Jr, SXLSQI: A Program for Modeling Solvent Extraction Systems, Oak Ridge National Laboratory report ORNL/TM-13604, December 1998

[5] C.F. Baes, Jr, Modeling Solvent Extraction Systems with SXFIT, Solv. Extr. Ion Exch., 19, $193-$ $213(2001)$

[6] F. J. Milero, in Water and Aqueous Solutions, R. A. Horne, Ed., Wiley-Interscience, New York (1972)

17] K.S. Pitzer, Activity Coefficients in Electrolyte Solutions, $2^{\text {nd }}$ Ed. K.S. Pitzer Ed., CRC Press, Boca Raton (1991)

[8] A.F.M.Barton, Handbook of solubility parameters and other cohesion parameters, $2^{\text {nd }}$ Ed., CRC Press, Boca Raton (1983)

[9] R. A. Peterson, Preparation of Simulated Waste Solutions for Solvent Extraction Testing, Report WSRC-RP-2000-00361, Westinghouse Savannah River Company, Aiken, SC, May 1, 2000.

[10] Result presented in report by Moyer et al. Caustic-Side Solvent Extraction Chemical and Physical Properties, Progress in FY 2000 and FY 2001, Table 3.3 


\section{APPENDIX}

Data points obtained experimentally and organized for modeling with the program

\begin{tabular}{|c|c|c|c|c|c|c|c|c|c|c|}
\hline $\mathrm{D}_{\text {value }}$ & Error & [Lig] & {$\left[\mathrm{Na}^{+}\right]$} & {$\left[\mathrm{K}^{+}\right]$} & {$\left[\mathrm{Cs}^{+}\right]$} & {$\left[\mathrm{H}^{+}\right]$} & {$\left[\mathrm{NO}_{3}{ }^{-}\right]$} & {$\left[\mathrm{OH}^{-}\right]$} & {$\left[\mathrm{NO}_{2}^{-}\right]$} & {$[\mathrm{Cl}]$} \\
\hline $1.39 E-02$ & $6.95 \mathrm{E}-04$ & 0.01 & $0.000 E+00$ & $0.00 \mathrm{E}+00$ & $1.00 E+00$ & $0.00 E+00$ & $1.00000 E+00$ & $0.0 E+00$ & $0.0 \mathrm{E}+00$ & $0.0 \mathrm{E}+00$ \\
\hline $1.34 \mathrm{E}-02$ & $6.70 \mathrm{E}-04$ & 0.01 & $0.000 E+00$ & $0.00 E+00$ & $1.00 E+00$ & $0.00 E+00$ & $1.00000 E+00$ & $0.0 E+00$ & $0.0 E+00$ & $0.0 E+00$ \\
\hline $5.03 \mathrm{E}-02$ & $2.52 \mathrm{E}-03$ & 0.01 & $0.000 \mathrm{E}+00$ & $0.00 \mathrm{E}+00$ & $3.00 \mathrm{E}-01$ & $0.00 \mathrm{E}+00$ & $3.00000 \mathrm{E}-01$ & $0.0 E+00$ & $0.0 E+00$ & $0.0 E+00$ \\
\hline 5.05E-02 & $2.53 E-03$ & 0.01 & $0.000 E+00$ & $0.00 E+00$ & $3.00 \mathrm{E}-01$ & $0.00 E+00$ & $3.00000 \mathrm{E}-01$ & $0.0 E+00$ & $0.0 \mathrm{E}+00$ & $0.0 E+00$ \\
\hline 1.07E-01 & $5.35 \mathrm{E}-03$ & 0.01 & $0.000 \mathrm{E}+00$ & $0.00 \mathrm{E}+00$ & $1.00 \mathrm{E}-01$ & $0.00 \mathrm{E}+00$ & $1.00000 \mathrm{E}-01$ & $0.0 E+00$ & $0.0 \mathrm{E}+00$ & $0.0 E+00$ \\
\hline $1.07 E .01$ & 5.35E-03 & 0.01 & $0.000 E+00$ & $0.00 E+00$ & $1.00 E-01$ & $0.00 \mathrm{E}+00$ & $1.00000 \mathrm{E}-01$ & $0.0 \mathrm{E}+00$ & $0.0 E+00$ & $0.0 E+00$ \\
\hline $2.69 \mathrm{E} \cdot 01$ & $1.35 E-02$ & 0.01 & $0.000 E+00$ & $0.00 \mathrm{E}+00$ & $3.00 \mathrm{E}-02$ & $0.00 \mathrm{E}+00$ & $3.00000 E-02$ & $0.0 E+00$ & $0.0 E+00$ & $0.0 E+00$ \\
\hline $2.34 E-01$ & $1.17 E-02$ & 0.01 & $0.000 E+00$ & $0.00 \mathrm{E}+00$ & $3.00 \mathrm{E}-02$ & $0.00 E+00$ & $3.00000 \mathrm{E}-02$ & $0.0 E+00$ & $0.0 E+00$ & $0.0 E+00$ \\
\hline $2.17 \mathrm{E}-01$ & $1.09 E-02$ & 0.01 & $0.000 E+00$ & $0.00 \mathrm{E}+00$ & $1.00 \mathrm{E}-02$ & $0.00 \mathrm{E}+00$ & $1.00000 E-02$ & $0.0 E+00$ & $0.0 E+00$ & $0.0 E+00$ \\
\hline $1.96 E-01$ & $9.80 \mathrm{E}-03$ & 0.01 & $0.000 E+00$ & $0.00 E+00$ & $1.00 E-02$ & $0.00 E+00$ & $1.00000 \mathrm{E}-02$ & $0.0 \mathrm{E}+00$ & $0.0 E+00$ & $0.0 E+00$ \\
\hline $4.41 E-02$ & $2.21 E-03$ & 0.01 & $0.000 E+00$ & $0.00 E+00$ & $5.00 \mathrm{E}-04$ & $1.00 \mathrm{E}-03$ & $1.50000 E-03$ & $0.0 E+00$ & $0.0 E+00$ & $0.0 \mathrm{E}+00$ \\
\hline $4.44 E-02$ & $2.22 \mathrm{E}-0.3$ & 0.01 & $0.000 \mathrm{E}+00$ & $0.00 \mathrm{E}+00$ & $5.00 \mathrm{E}-04$ & $1.00 \mathrm{E}-03$ & $1.50000 \mathrm{E}-03$ & $0.0 \mathrm{E}+00$ & $0.0 E+00$ & $0.0 E+00$ \\
\hline $1.26 \mathrm{E}-01$ & $6.30 \mathrm{E}-03$ & 0.01 & $0.000 E+00$ & $0.00 E+00$ & $5.00 E-04$ & $3.00 \mathrm{E}-03$ & $3.50000 \mathrm{E}-03$ & $0.0 E+00$ & $0.0 E+00$ & $0.0 E+00$ \\
\hline $1.24 \mathrm{E}-01$ & $6.20 \mathrm{E}-03$ & 0.01 & $0.000 \mathrm{E}+00$ & $0.00 \mathrm{E}+00$ & $5.00 E-04$ & 3.00E-03 & $3.50000 \mathrm{E}-03$ & $0.0 E+00$ & $0.0 E+00$ & $0.0 E+00$ \\
\hline $3.48 \mathrm{E}-01$ & $1.74 \mathrm{E}-02$ & 0.01 & $0.000 E+00$ & $0.00 E+00$ & $5.00 \mathrm{E}-04$ & $1.00 \mathrm{E}-02$ & $1.05000 \mathrm{E}-02$ & $0.0 E+00$ & $0.0 \mathrm{E}+00$ & $0.0 E+00$ \\
\hline $2.85 \mathrm{E}-01$ & $1.43 E-02$ & 0.01 & $0.000 E+00$ & $0.00 E+00$ & $5.00 E-04$ & $1.00 \mathrm{E}-02$ & 1.05000 E-02 & $0.0 E+00$ & $0.0 E+00$ & $0.0 E+00$ \\
\hline $1.46 E+00$ & $7.30 \mathrm{E}-02$ & 0.01 & $0.000 \mathrm{E}+00$ & $0.00 E+00$ & $5.00 E-04$ & $5.00 \mathrm{E}-02$ & $5.05000 \mathrm{E}-02$ & $0.0 E+00$ & $0.0 E+00$ & $0.0 E+00$ \\
\hline $1.46 E+00$ & $7.30 \mathrm{E}-02$ & 0.01 & $0.000 E+00$ & $0.00 E+00$ & $5.00 \mathrm{E}-04$ & $5.00 \mathrm{E}-02$ & $5.05000 \mathrm{E}-02$ & $0.0 E+00$ & $0.0 \mathrm{E}+00$ & $.0 \mathrm{E}+00$ \\
\hline $2.52 E+00$ & $1.26 \mathrm{E}-01$ & 0.01 & $0.000 E+00$ & $0.00 \mathrm{E}+00$ & $5.00 \mathrm{E}-04$ & $1.00 \mathrm{E}-01$ & 1.00500 E-01 & $0.0 E+00$ & $0.0 E+00$ & $.0 E+00$ \\
\hline $2.47 E+00$ & $1.24 \mathrm{E}-01$ & 0.01 & $0.000 E+00$ & $0.00 E+00$ & $5.00 \mathrm{E}-04$ & $1.00 \mathrm{E}-01$ & $1.00500 \mathrm{E}-01$ & $0.0 E+00$ & $0.0 E+00$ & $.0 E+00$ \\
\hline $3.78 \mathrm{E}-01$ & $1.89 \mathrm{E}-02$ & 0.01 & $1.000 \mathrm{E}-02$ & $0.00 \mathrm{E}+00$ & $5.00 \mathrm{E}-04$ & $0.00 E+00$ & $1.05000 E-02$ & $0.0 E+00$ & $.0 E+00$ & $.0 E+00$ \\
\hline $3.68 \mathrm{E}-01$ & $1.84 \mathrm{E}-02$ & 0.01 & $1.000 \mathrm{E}-02$ & $0.00 \mathrm{E}+00$ & $5.00 \mathrm{E}-04$ & $0.00 E+00$ & $1.05000 \mathrm{E}-02$ & $0.0 E+00$ & $0.0 E+00$ & $.0 \mathrm{E}+00$ \\
\hline $2.50 E+00$ & 1.25E-01 & 0.01 & $1.000 \mathrm{E}-01$ & $0.00 E+00$ & $5.00 \mathrm{E}-04$ & $0.00 E+00$ & $1.00500 \mathrm{E}-01$ & $0.0 E+00$ & $0.0 \mathrm{E}+00$ & $0.0 E+00$ \\
\hline $2.50 E+00$ & 1.25E-01 & 0.01 & $1.000 E-01$ & $0.00 E+00$ & $5.00 \mathrm{E}-04$ & $0.00 \mathrm{E}+00$ & $1.00500 E-01$ & $0.0 E+00$ & $0.0 E+00$ & $0.0 E+00$ \\
\hline $7.14 E+00$ & $3.57 \mathrm{E}-01$ & 0.01 & $5.000 E-01$ & $0.00 E+00$ & $5.00 E-04$ & $0.00 E+00$ & $5.00500 \mathrm{E}-01$ & $0.0 E+00$ & $0.0 E+00$ & $0.0 \mathrm{E}+00$ \\
\hline $7.23 E+00$ & 3.62E-01 & 0.01 & $5.000 \mathrm{E} \cdot 01$ & $0.00 E+00$ & $5.00 \mathrm{E}-04$ & $0.00 E+00$ & $5.00500 E-01$ & $0.0 E+00$ & $0.0 \mathrm{E}+00$ & $0.0 \mathrm{E}+00$ \\
\hline $9.84 E+00$ & $4.92 \mathrm{E}-01$ & 0.01 & $1.000 \mathrm{E}+00$ & $0.00 \mathrm{E}+00$ & $5.00 \mathrm{E}-04$ & $0.00 E+00$ & $1.00050 E+00$ & $0.0 E+00$ & $0.0 E+00$ & $0.0 E+00$ \\
\hline $9.87 E+00$ & $4.94 \mathrm{E}-01$ & 0.01 & $1.000 E+00$ & $0.00 E+00$ & $5.00 E-04$ & $0.00 E+00$ & $1.00050 \mathrm{E}+00$ & $0.0 E+00$ & $0.0 E+00$ & $0.0 E+00$ \\
\hline $1.08 E+01$ & $5.40 \mathrm{E}-01$ & 0.01 & $2.250 \mathrm{E}+00$ & $0.00 E+00$ & 5.00E-04 & $0.00 \mathrm{E}+00$ & $2.25050 E+00$ & $0.0 E+00$ & $0.0 E+00$ & $0.0 E+00$ \\
\hline $1.09 E+01$ & $5.45 \mathrm{E}-01$ & 0.01 & $2.250 \mathrm{E}+00$ & $0.00 E+00$ & $5.00 \mathrm{E}-04$ & $0.00 E+00$ & $2.25050 E+00$ & $0.0 E+00$ & $0.0 E+00$ & $0.0 \mathrm{E}+00$ \\
\hline $9.00 E+00$ & $4.50 E-01$ & 0.01 & $4.500 E+00$ & $0.00 E+00$ & $5.00 E-04$ & $0.00 E+00$ & $4.50050 E+00$ & $0.0 E+00$ & $0.0 E+00$ & $0.0 E+00$ \\
\hline $8.95 E+00$ & $4.48 \mathrm{E}-01$ & 0.01 & $4.500 \mathrm{E}+00$ & $0.00 E+00$ & $5.00 E-04$ & $0.00 \mathrm{E}+00$ & $4.50050 E+00$ & $0.0 E+00$ & $0.0 \mathrm{E}+00$ & $0.0 \mathrm{E}+00$ \\
\hline $7.96 E+00$ & $3.98 E-01$ & 0.01 & $5.600 \mathrm{E}+00$ & $0.00 E+00$ & $5.00 E-04$ & $0.00 E+00$ & $5.60050 \mathrm{E}+00$ & $0.0 \mathrm{E}+00$ & $0.0 \mathrm{E}+00$ & $0.0 \mathrm{E}+00$ \\
\hline $7.84 E+00$ & $3.92 \mathrm{E}-01$ & 0.01 & $5.600 \mathrm{E}+00$ & $0.00 E+00$ & $5.00 E-04$ & $0.00 E+00$ & $5.60050 \mathrm{E}+00$ & $0.0 E+00$ & $0.0 E+00$ & $0.0 E+00$ \\
\hline $5.78 \mathrm{E}-03$ & $2.89 E-04$ & 0.01 & $0.000 E+00$ & $1.51 E+00$ & $0.00 \mathrm{E}+00$ & $0.00 E+00$ & $1.51000 \mathrm{E}+00$ & $0.0 \mathrm{E}+00$ & $0.0 \mathrm{E}+00$ & $0.0 \mathrm{E}+00$ \\
\hline $5.66 \mathrm{E}-03$ & $2.83 E-04$ & 0.01 & $0.000 E+00$ & $1.51 E+00$ & $0.00 E+00$ & $0.00 E+00$ & $1.51000 \mathrm{E}+00$ & $0.0 E+00$ & $0.0 \mathrm{E}+00$ & $0.0 \mathrm{E}+00$ \\
\hline $9.92 \mathrm{E}-03$ & $4.96 \mathrm{E}-04$ & 0.01 & $0.000 E+00$ & $7.55 \mathrm{E}-01$ & $0.00 E+00$ & $0.00 E+00$ & $7.55000 E-01$ & $0.0 E+00$ & $0.0 E+00$ & $0.0 E+00$ \\
\hline $9.95 E-03$ & 4.98E-04 & 0.01 & $0.000 E+00$ & $7.55 \mathrm{E}-01$ & $0.00 \mathrm{E}+00$ & $0.00 E+00$ & 7.55000 E- 01 & $0.0 E+00$ & $0.0 E+00$ & $0.0 E+00$ \\
\hline $1.30 E-02$ & $6.49 \mathrm{E}-04$ & 0.01 & $0.000 E+00$ & $3.00 \mathrm{E}-01$ & $0.00 \mathrm{E}+00$ & $0.00 E+00$ & 3.00000 E -01 & $0.0 E+00$ & $0.0 E+00$ & $0.0 \mathrm{E}+00$ \\
\hline 1.33E-02 & $6.65 \mathrm{E}-04$ & 0.01 & $0.000 \mathrm{E}+00$ & $3.00 E-01$ & $0.00 E+00$ & $0.00 E+00$ & $3.00000 \mathrm{E}-01$ & $0.0 \mathrm{E}+00$ & $0.0 E+00$ & $0.0 E+00$ \\
\hline $8.15 E-03$ & $4.07 \mathrm{E}-04$ & 0.01 & $0.000 \mathrm{E}+00$ & $1.00 E-01$ & $0.00 E+00$ & $0.00 E+00$ & $1.00000 \mathrm{E}-01$ & $0.0 \mathrm{E}+00$ & $0.0 \mathrm{E}+00$ & $0.0 \mathrm{E}+00$ \\
\hline $8.36 \mathrm{E}-03$ & $4.18 \mathrm{E}-04$ & 0.01 & $0.000 E+00$ & $1.00 \mathrm{E}-01$ & $0.00 \mathrm{E}+00$ & $0.00 E+00$ & $1.00000 E-01$ & $0.0 E+00$ & $0.0 E+00$ & $0.0 E+00$ \\
\hline $1.13 E-02$ & $5.66 \mathrm{E}-04$ & 0.01 & $9.400 \mathrm{E}-03$ & $6.00 \mathrm{E}-02$ & $0.00 E+00$ & $0.00 E+00$ & $6.94000 \mathrm{E}-02$ & $0.0 E+00$ & $0.0 E+00$ & $0.0 \mathrm{E}+00$ \\
\hline $1.12 E-02$ & $5.58 \mathrm{E}-04$ & 0.01 & $9.400 \mathrm{E}-03$ & $6.00 E-02$ & $0.00 E+00$ & $0.00 E+00$ & 6.94000 E -02 & $0.0 E+00$ & $0.0 \mathrm{E}+00$ & $0.0 E+00$ \\
\hline $1.95 E-02$ & 9.77E-04 & 0.01 & $9.400 \mathrm{E}-02$ & $6.00 E-02$ & $0.00 E+00$ & $0.00 E+00$ & $1.54000 \mathrm{E}-01$ & $0.0 E+00$ & $0.0 E+00$ & $0.0 E+00$ \\
\hline $1.97 \mathrm{E}-02$ & $9.83 E-04$ & 0.01 & $9.400 \mathrm{E}-02$ & $6.00 E-02$ & $0.00 E+00$ & $0.00 E+00$ & $1.54000 \mathrm{E}-01$ & $0.0 E+00$ & $0.0 \mathrm{E}+00$ & $0.0 E+00$ \\
\hline $3.81 \mathrm{E}-02$ & $1.91 E-03$ & 0.01 & $4.700 E-01$ & $6.00 E-02$ & $0.00 E+00$ & $0.00 E+00$ & $5.30000 \mathrm{E}-01$ & $0.0 E+00$ & $0.0 E+00$ & $0.0 E+00$ \\
\hline $3.81 \mathrm{E}-02$ & $1.90 E-03$ & 0.01 & $4.700 \mathrm{E}-01$ & $6.00 E-02$ & $0.00 E+00$ & $0.00 E+00$ & $5.30000 E-01$ & $0.0 E+00$ & $0.0 E+00$ & $0.0 E+00$ \\
\hline $4.86 \mathrm{E}-02$ & $2.43 E-03$ & 0.01 & $9.400 \mathrm{E}-01$ & $6.00 E-02$ & $0.00 \mathrm{E}+00$ & $0.00 \mathrm{E}+00$ & $1.00000 \mathrm{E}+00$ & $0.0 E+00$ & $0.0 E+00$ & $0.0 E+00$ \\
\hline $5.48 \mathrm{E}-02$ & $2.74 \mathrm{E}-03$ & 0.01 & $2.162 E+00$ & $6.00 \mathrm{E}-02$ & $0.00 E+00$ & $0.00 E+00$ & $2.22200 E+00$ & $0.0 \mathrm{E}+00$ & $0.0 \mathrm{E}+00$ & $0.0 E+00$ \\
\hline $5.51 \mathrm{E}-02$ & $2.75 \mathrm{E}-03$ & 0.01 & $2.162 E+00$ & $6.00 E-02$ & $0.00 E+00$ & $0.00 E+00$ & $2.22200 E+00$ & $0.0 E+00$ & $0.0 \mathrm{E}+00$ & $0.0 E+00$ \\
\hline $5.01 \mathrm{E}-02$ & $2.51 E-03$ & 0.01 & $4.230 \mathrm{E}+00$ & $6.00 \mathrm{E}-02$ & $0.00 E+00$ & $0.00 E+00$ & $4.29000 E+00$ & $0.0 E+00$ & $0.0 E+00$ & $0.0 E+00$ \\
\hline $5.00 E-02$ & $2.50 \mathrm{E}-03$ & 0.01 & $4.230 E+00$ & $6.00 \mathrm{E}-02$ & $0.00 E+00$ & $0.00 E+00$ & $4.29000 E+00$ & $0.0 E+00$ & $0.0 \mathrm{E}+00$ & $0.0 E+00$ \\
\hline $4.41 E-02$ & $2.20 \mathrm{E}-03$ & 0.01 & $5.264 \mathrm{E}+00$ & $6.00 \mathrm{E}-02$ & $0.00 E+00$ & $0.00 E+00$ & $5.32400 E+00$ & $0.0 E+00$ & $0.0 E+00$ & $0.0 E+00$ \\
\hline
\end{tabular}




\begin{tabular}{|c|c|c|c|c|c|c|c|c|c|c|}
\hline $4.74 E-02$ & $37 E-03$ & 0.01 & $5.264 E+00$ & $6.00 E-02$ & $0.00 E+00$ & $0.00 E+00$ & $5.32400 E+00$ & $0.0 E+00$ & $0.0 E+00$ & $0.0 E+00$ \\
\hline $9.33 E-03$ & 4.67E-04 & 0.01 & $1.000 \mathrm{E}-02$ & $6.00 E-02$ & $5.00 E-04$ & $0.00 E+00$ & $7.05000 \mathrm{E}-02$ & $0.0 E+00$ & $0.0 E+00$ & $0.0 E+00$ \\
\hline $9.37 E-03$ & $4.69 \mathrm{E}-04$ & 0.01 & $1.000 \mathrm{E}-02$ & $6.00 E-02$ & $5.00 E-04$ & $0.00 E+00$ & $7.05000 E-02$ & $0.0 E+00$ & $0.0 E+00$ & $0.0 E+00$ \\
\hline $1.66 \mathrm{E}-02$ & $8.31 E-04$ & 0.01 & $1.000 E-01$ & $6.00 E-02$ & $5.00 E-04$ & $0.00 E+00$ & $1.60500 \mathrm{E}-01$ & $0.0 \mathrm{E}+00$ & $0.0 E+00$ & $0.0 E+00$ \\
\hline $1.67 \mathrm{E}-02$ & $8.36 E-04$ & 0.01 & $1.000 E-01$ & $6.00 E-02$ & $5.00 E-04$ & $0.00 E+00$ & $1.60500 \mathrm{E}-01$ & $0.0 E+00$ & $0.0 \mathrm{E}+00$ & $0.0 E+00$ \\
\hline $3.13 E-02$ & $1.57 E-03$ & 0.01 & 5.000 E- 01 & $6.00 E-02$ & $5.00 E-04$ & $0.00 E+00$ & $5.60500 \mathrm{E}-01$ & $0.0 E+00$ & $0.0 E+00$ & $0.0 E+00$ \\
\hline $3.20 \mathrm{E}-02$ & $1.60 E-03$ & 0.01 & 5.000 E-01 & $6.00 E-02$ & $5.00 \mathrm{E}-04$ & $0.00 E+00$ & $5.60500 E-01$ & $0.0 E+00$ & $0.0 \mathrm{E}+00$ & $0.0 E+00$ \\
\hline $4.04 \mathrm{E}-02$ & $2.02 E-03$ & 0.01 & $1.000 E+00$ & $6.00 E-02$ & $5.00 E-04$ & $0.00 E+00$ & $1.06050 \mathrm{E}+00$ & $0.0 \mathrm{E}+00$ & $1.0 E+00$ & $.0 E+00$ \\
\hline $4.10 E-02$ & $2.05 E-03$ & 0.01 & $1.000 E+00$ & $8.00 E-02$ & $5.00 E-04$ & $0.00 E+00$ & $1.06050 E+00$ & $0.0 E+00$ & $0.0 E+00$ & $.0 E+00$ \\
\hline $4.78 \mathrm{E}-02$ & $2.39 E-03$ & 0.01 & $2.250 E+00$ & $6.00 E-02$ & $5.00 \mathrm{E}-04$ & $0.00 E+00$ & $2.31050 E+00$ & $0.0 E+00$ & $.0 E+00$ & $.0 E+00$ \\
\hline $4.66 \mathrm{E}-02$ & $2.33 E-03$ & 0.01 & $2.250 E+00$ & $6.00 \mathrm{E} \cdot 02$ & $5.00 E-04$ & $0.00 E+00$ & $2.31050 E+00$ & $0.0 E+00$ & $0 \mathrm{E}+00$ & \\
\hline 4.21E-02 & $2.10 E-03$ & 0.01 & $4.500 E+00$ & $6.00 E-02$ & $5.00 E-04$ & $0.00 E+00$ & $4.56050 E+00$ & $0.0 E+00$ & $0 E+00$ & \\
\hline $4.31 E-02$ & $2.16 \mathrm{E}-03$ & 0.01 & $4.500 E+00$ & $6.00 E-02$ & $5.00 E-04$ & $0.00 E+00$ & $4.56050 E+00$ & $0.0 E+00$ & $0 E+00$ & $E+00$ \\
\hline $4.04 \mathrm{E}-02$ & $2.02 E-03$ & 0.01 & & & & $0.00 E+00$ & & & & \\
\hline $3.87 \mathrm{E}-02$ & $1.94 E-03$ & 0.01 & $5.600 E+00$ & $6.00 E-02$ & $5.00 \mathrm{E}-04$ & $0.00 E+00$ & $5.66050 E+00$ & $0.0 E+00$ & $.0 E+00$ & +00 \\
\hline $8.82 E-03$ & & & & & & & & & & \\
\hline $8.97 \mathrm{E}-03$ & $4.49 E-04$ & 0.01 & $0.000 \mathrm{E}+00$ & $6.00 E \cdot 02$ & $5.00 E-04$ & $E-03$ & $0 E-02$ & $0.0 E+00$ & $E+00$ & \\
\hline $8.98 \mathrm{E}-03$ & $4.49 E-04$ & 0.01 & $0.000 E+00$ & $6.00 E-02$ & $5.00 \mathrm{E}-04$ & & $0 E .02$ & $0.0 E+00$ & $E+00$ & \\
\hline $9.19 \mathrm{E}-03$ & $4.59 E-04$ & .01 & $0.000 E+00$ & $6.00 E-02$ & $5.00 E-04$ & & $6.35000 \mathrm{E}-02$ & +00 & & \\
\hline $9.78 \mathrm{E}-03$ & $4.89 E-04$ & 0.01 & $0.000 E+00$ & $6.00 E-02$ & $5.00 E-04$ & & $7.05000 E-02$ & & & \\
\hline E-02 & & 0.01 & & & & & & & & \\
\hline$=-02$ & $6.82 E-04$ & 0.01 & +00 & $6.00 \mathrm{E}-02$ & $E=04$ & $E-02$ & $\mathrm{OE}-01$ & $0.0 E+00$ & +00 & \\
\hline & & & & & & & & & & \\
\hline $1.78 E-02$ & $8.92 E-04$ & 0.01 & $E+00$ & $6.00 E-02$ & 0.04 & $E-01$ & $0 \mathrm{E}-01$ & $0.0 E+00$ & $E+\infty$ & \\
\hline$E-02$ & & & & & & & & & & \\
\hline $2.94 \mathrm{E}-03$ & 1.47 & & +00 & E-02 & $+\infty$ & & $E-02$ & & & \\
\hline & & 0.01 & $E+\infty$ & $1.00 E-02$ & $E+00$ & & $E-02$ & & & \\
\hline 1.2 & & & +00 & $1.00 E-01$ & +00 & & $E-01$ & & & \\
\hline & & 0.0 & +00 & $E-01$ & +00 & & $E-01$ & & & \\
\hline 0.02 & 7.9 & 0.01 & +00 & E-01 & $E+00$ & +00 & $8-01$ & +00 & +00 & \\
\hline$E-02$ & 7.92 & & +00 & E-01 & +00 & & $E-01$ & +00 & +00 & \\
\hline 0.03 & & 0.0 & \pm 00 & $E+00$ & $E+00$ & 0.0 & $E+00$ & +00 & $=+00$ & \\
\hline-03 & $4.56 E-04$ & 0.01 & $0.000 \mathrm{E}+00$ & $1.00 E+00$ & $0.00 E+00$ & $0.00 E+00$ & $00 E+00$ & $0.0 E+00$ & $E+00$ & $E+00$ \\
\hline & & & & & & & & & $E+00$ & \\
\hline$E-01$ & $1.2 f$ & & & +00 & -04 & +00 & & -02 & 00 & \\
\hline & & & & & & & & & & \\
\hline+00 & 6.30 & 0.01 & 1.00 & $0.00 \mathrm{E}+00$ & $5.00 E-04$ & +00 & -04 & -01 & +00 & \\
\hline & & & & & & & & & & \\
\hline 4.96 & 2.48 & & & $E+00$ & & & & & +00 & \\
\hline & & & & & & & & & & \\
\hline $8.65 E+00$ & & & & & & & & $E+00$ & 00 & \\
\hline 2.83 & & & & & & & & & & \\
\hline & & & & & & & & & & \\
\hline & & 0.0 & & & & & & & & \\
\hline & & & & & & & & & & \\
\hline 1.02 & & & & & & & & & & $E+00$ \\
\hline & & & & & & & & & & \\
\hline$E-03$ & & & & & & & & & $E+00$ & $E+00$ \\
\hline & & & & & & & & & & \\
\hline & & 0.00 & & $0.00 \mathrm{E}+00$ & E-04 & & & & $0.00 E+00$ & \pm+00 \\
\hline & & & & & & & & & & \\
\hline $6.32 E-03$ & $E-04$ & 0.00 & & $0.00 E+00$ & $5.00 \mathrm{E}-04$ & & & 2.2 & $0.00 E+00$ & $0.00 E+00$ \\
\hline & & & & & & & & & & \\
\hline & & 0.00 & & & $E-04$ & & & & & \\
\hline 1.73 & & & & & & 0.0 & & & $E+00$ & \\
\hline & & & & & & & & & & \\
\hline $2.96 \mathrm{E}-02$ & $1.48 \mathrm{E}-03$ & 0.00 & & $0.00 E+00$ & $5.00 E-04$ & $0.00 E+00$ & & & & \\
\hline & & & & & & & & & & \\
\hline $8.07 E-03$ & $4.04 E-04$ & 0.0 & 2.00 & & $1.00 E+00$ & $0.00 E+00$ & +00 & & 00 & \\
\hline $2.75 E-02$ & & & & & & & & & & \\
\hline & & & & & & & & & & \\
\hline $6.63 \mathrm{E}-02$ & $3.32 \mathrm{E}-03$ & 0.0 & & $0.00 E+00$ & & & & & $0.00 E+00$ & $0.00 E+00$ \\
\hline & & & & & & & & & & \\
\hline $3.44 E-01$ & $1.72 \mathrm{E}-02$ & 0.01 & $2.00 E+00$ & $0.00 E+00$ & $3.00 \mathrm{E}-02$ & $0.00 E+00$ & $3.0000 \mathrm{E}-02$ & $2.00 \mathrm{E}+00$ & $0.00 \mathrm{E}+00$ & $0.00 E+00$ \\
\hline
\end{tabular}




\begin{tabular}{|c|c|c|c|c|c|c|c|c|c|c|}
\hline $3.14 \mathrm{E}-01$ & $1.57 \mathrm{E}-02$ & 0.01 & $2.00 E+00$ & $0.00 \mathrm{E}+00$ & $3.00 \mathrm{E}-02$ & $0.00 E+00$ & $3.0000 \mathrm{E}-02$ & $2.00 E+00$ & $0.00 E+00$ & $0.00 E+00$ \\
\hline $3.35 E+00$ & $1.68 \mathrm{E}-01$ & 0.01 & $2.00 E+00$ & $0.00 E+00$ & $1.00 \mathrm{E}-02$ & $0.00 \mathrm{E}+00$ & 1.0000 E-02 & $2.00 E+00$ & $0.00 E+00$ & $0.00 E+00$ \\
\hline $3.02 E+00$ & 1.51E-01 & 0.01 & $2.00 E+00$ & $0.00 E+00$ & $1.00 \mathrm{E}-02$ & $0.00 \mathrm{E}+00$ & $1.0000 \mathrm{E}-02$ & $2.00 E+00$ & $0.00 E+00$ & $0.00 E+00$ \\
\hline $5.07 E+00$ & $2.54 \mathrm{E}-01$ & 0.01 & $2.00 E+00$ & $0.00 E+00$ & $3.00 \mathrm{E}-03$ & $0.00 E+00$ & $3.0000 \mathrm{E}-03$ & $2.00 E+00$ & $0.00 \mathrm{E}+00$ & $0.00 E+00$ \\
\hline $5.09 \mathrm{E}+00$ & $2.55 \mathrm{E}-01$ & 0.01 & $2.00 E+00$ & $0.00 E+00$ & $3.00 \mathrm{E}-03$ & $0.00 E+00$ & $3.0000 E-03$ & $2.00 \mathrm{E}+00$ & $0.00 E+00$ & $0.00 E+00$ \\
\hline $1.36 \mathrm{E}+01$ & $6.80 \mathrm{E}-01$ & 0.01 & $2.00 \mathrm{E}+00$ & $0.00 \mathrm{E}+00$ & $1.00 \mathrm{E}-03$ & $0.00 E+00$ & $1.0000 E-03$ & $2.00 E+00$ & $0.00 E+00$ & $0.00 \mathrm{E}+00$ \\
\hline $1.48 E+01$ & $7.40 E-01$ & 0.01 & $2.00 E+00$ & $0.00 E+00$ & $1.00 E-03$ & $0.00 \mathrm{E}+00$ & $1.0000 E-03$ & $2.00 E+00$ & $0.00 E+00$ & $0.00 E+00$ \\
\hline $1.48 \mathrm{E}+01$ & $7.40 \mathrm{E}-01$ & 0.01 & $2.00 \mathrm{E}+00$ & $0.00 E+00$ & $3.00 \mathrm{E}-04$ & $0.00 E+00$ & 3.0000 E-04 & $2.00 E+00$ & $0.00 E+00$ & $0.00 E+00$ \\
\hline $1.56 \mathrm{E}+01$ & $7.80 \mathrm{E}-01$ & 0.01 & $2.00 E+00$ & $0.00 E+00$ & $3.00 \mathrm{E}-04$ & $0.00 E+00$ & $3.0000 \mathrm{E}-04$ & $2.00 E+00$ & $0.00 E+00$ & $0.00 E+00$ \\
\hline $1.49 E+01$ & $7.45 \mathrm{E}-01$ & 0.01 & $2.00 \mathrm{E}+00$ & $0.00 E+00$ & $1.00 \mathrm{E}-04$ & $0.00 E+00$ & $1.0000 \mathrm{E}-04$ & $2.00 E+00$ & $0.00 E+00$ & $0.00 E+00$ \\
\hline $1.48 \mathrm{E}+01$ & $7.40 \mathrm{E}-01$ & 0.01 & $2.00 E+00$ & $0.00 E+00$ & $1.00 E-04$ & $0.00 E+00$ & $1.0000 \mathrm{E}-04$ & $2.00 E+00$ & $0.00 E+00$ & $0.00 \mathrm{E}+00$ \\
\hline $7.96 \mathrm{E}+00$ & 3.98E-01 & 0.01 & $5.60 E+00$ & $0.00 E+00$ & $5.00 E-04$ & $0.00 \mathrm{E}+00$ & $5.6005 E+00$ & $0.00 \mathrm{E}+00$ & $0.00 E+00$ & $0.00 E+00$ \\
\hline $7.84 E+00$ & 3.92E-01 & 0.01 & $5.60 E+00$ & $0.00 \varepsilon+00$ & $5.00 E-04$ & $0.00 E+00$ & $5.6005 E+00$ & $0.00 E+00$ & $0.00 E+00$ & $0.00 E+00$ \\
\hline $9.98 E+00$ & $4.99 E-01$ & 0.01 & $5.60 \mathrm{E}+00$ & $0.00 E+00$ & $5.00 E-04$ & $0.00 E+00$ & $5.0405 E+00$ & $5.60 \mathrm{E}-01$ & $0.00 E+00$ & $0.00 \mathrm{E}+00$ \\
\hline $9.88 E+00$ & $4.94 \mathrm{E}-01$ & 0.01 & $5.60 E+00$ & $0.00 E+00$ & $5.00 \mathrm{E}-04$ & $0.00 E+00$ & $5.0405 \mathrm{E}+00$ & $5.60 E-01$ & $0.00 \mathrm{E}+00$ & \\
\hline $1.33 E+01$ & $6.65 E-01$ & 0.01 & $5.60 E+00$ & $0.00 E+00$ & $5.00 \mathrm{E}-04$ & $0.00 \mathrm{E}+00$ & $4.2005 E+00$ & $1.40 E+00$ & $0.00 E+00$ & $0.00 E+00$ \\
\hline $1.31 E+01$ & $6.55 E-01$ & 0.01 & $5.60 \mathrm{E}+00$ & $0.00 E+00$ & $5.00 E-04$ & $0.00 E+00$ & $4.2005 E+00$ & $1.40 E+00$ & $0.00 E+00$ & $0.00 E+00$ \\
\hline $2.51 \mathrm{E}+01$ & $1.26 \mathrm{E}+00$ & 0.01 & $5.60 E+00$ & $0.00 E+00$ & $5.00 E-04$ & $0.00 E+00$ & $2.8005 E+00$ & $2.80 E+00$ & $0.00 \mathrm{E}+00$ & $E+00$ \\
\hline $2.31 E+01$ & $1.16 E+00$ & 0.01 & $5.60 E+00$ & $0.00 E+00$ & $5.00 E-04$ & $0.00 \mathrm{E}+00$ & $2.8005 E+00$ & $2.80 E+00$ & $E+00$ & +00 \\
\hline $4.71 E+01$ & $2.36 \mathrm{E}+00$ & 0.01 & $5.60 E+00$ & $0.00 E+00$ & $5.00 E-04$ & $0 E+00$ & $1.4005 E+00$ & $4.20 E+00$ & $E+00$ & \\
\hline $4.74 E+01$ & $2.37 E+00$ & 0.01 & $5.60 \mathrm{E}+00$ & $0.00 E+00$ & $5.00 \mathrm{E}-04$ & $0.00 E+00$ & $05 E+00$ & $E+00$ & $E+00$ & $E+00$ \\
\hline $1.02 E+02$ & $5.10 E+00$ & 0.01 & $5.60 E+00$ & $0.00 E+00$ & $5.00 E-04$ & $0 \mathrm{E}+0 \mathrm{O}$ & $0 E-04$ & $E+00$ & $O E+00$ & \\
\hline $9.88 E+01$ & $4.94 \mathrm{E}+00$ & 0.01 & $\mathrm{DE}+00$ & $0.00 E+00$ & $5.00 E-04$ & $E+\infty$ & E-04 & $E+00$ & $O E+00$ & \\
\hline $1.07 E-02$ & $5.34 \mathrm{E} \cdot 04$ & 0.01 & $1.00 E-02$ & $6 E-02$ & $5.00 E-04$ & $E+\infty 0$ & E-02 & $1.000 \mathrm{E}-02$ & $0.00 E+00$ & $0.00 E+00$ \\
\hline $1.03 \mathrm{E}-02$ & $5.13 E-04$ & 0.01 & $1.00 E-02$ & $6 E-02$ & $5.00 E-04$ & $0.00 E+00$ & $6.05 \mathrm{E}-02$ & $1.000 \mathrm{E}-02$ & $0.00 \mathrm{E}+00$ & $0.00 E+00$ \\
\hline $2.07 E-02$ & 1.03E-03 & 0.01 & 1.00E-01 & $6 \mathrm{E}-02$ & $5.00 E-04$ & $0.00 \mathrm{E}+00$ & $6.05 \mathrm{E}-02$ & 1.000 E-01 & $0.00 E+00$ & $0.00 E+00$ \\
\hline $2.08 E-02$ & $1.04 \mathrm{E}-03$ & 0.01 & $1.00 \mathrm{E}-01$ & $6 E-02$ & $5.00 E-04$ & $0.00 E+00$ & $6.05 \mathrm{E}-02$ & $1.000 E-01$ & $0.00 E+00$ & $0.00 E+00$ \\
\hline $4.90 E-02$ & $2.45 E-03$ & 0.01 & $5.00 \mathrm{E}-01$ & $6 \mathrm{E}-02$ & $5.00 \mathrm{E}-04$ & $0.00 E+00$ & $6.05 \mathrm{E}-02$ & $5.000 \mathrm{E}-01$ & $0.00 E+00$ & $0.00 E+00$ \\
\hline $5.11 E-02$ & $2.55 E-03$ & 0.01 & $5.00 \mathrm{E}-01$ & $6 \mathrm{E}-02$ & $5.00 \mathrm{E}-04$ & $0.00 E+00$ & $6.05 \mathrm{E}-02$ & $5.000 \mathrm{E}-01$ & $0.00 \mathrm{E}+00$ & $0.00 E+00$ \\
\hline $7.44 \mathrm{E}-02$ & $3.72 E-03$ & 0.01 & $1.00 E+00$ & $6 \mathrm{E} \cdot 02$ & $5.00 \mathrm{E}-04$ & $0.00 E+00$ & $6.05 E-02$ & $1.000 E+00$ & $0.00 E+00$ & $0.00 E+00$ \\
\hline 7.67E-02 & 3.83E.03 & 0.01 & $1.00 E+00$ & $6 \mathrm{E}-02$ & $5.00 \mathrm{E}-04$ & $0.00 \mathrm{E}+00$ & & $1.000 E+00$ & $0.00 E+00$ & $0.00 \mathrm{E}+00$ \\
\hline $1.18 \mathrm{E}-01$ & $5.88 \mathrm{E}-03$ & 0.01 & $2.25 E+00$ & $6 E-02$ & $5.00 E-04$ & $0.00 E+00$ & $6.05 E-02$ & $2.250 E+00$ & $0.00 E+00$ & $0.00 E+00$ \\
\hline $1.22 \mathrm{E}-01$ & $6.10 \mathrm{E}-03$ & 0.01 & $2.25 E+00$ & $6 \mathrm{E}-02$ & $5.00 E-04$ & $0.00 E+00$ & $6.05 \mathrm{E}-02$ & $2.250 E+00$ & $0.00 E+00$ & $0.00 \mathrm{E}+00$ \\
\hline $1.31 E-01$ & $6.54 E-03$ & 0.01 & $4.50 E+00$ & $6 \mathrm{E}-02$ & $5.00 \mathrm{E}-04$ & $0.00 E+00$ & 6.0 & $4.500 E+00$ & $0.00 E+00$ & $E+00$ \\
\hline $1.36 E-01$ & $6.79 \mathrm{E}-03$ & 0.01 & $4.50 E+00$ & $6 \mathrm{E} .02$ & $5.00 E-04$ & $E+00$ & $6.05 E$ & $4.500 \mathrm{E}+00$ & $0.00 E+00$ & $E+00$ \\
\hline $1.26 \mathrm{E}-01$ & $6.29 \mathrm{E}-03$ & 0.01 & $5.60 \mathrm{E}+00$ & $6 \mathrm{E}-02$ & $5.00 E-04$ & $0.00 E+00$ & $6.05 E-02$ & $5.600 \mathrm{E}+00$ & $0.00 \mathrm{E}+00$ & $0.00 E+00$ \\
\hline $1.39 \mathrm{E}-01$ & $6.94 \mathrm{E}-03$ & 0.01 & $5.60 \mathrm{E}+00$ & $6 \mathrm{E}-02$ & $5.00 \mathrm{E}-04$ & $0.00 \mathrm{E}+00$ & $6.05 \mathrm{E}-02$ & $5.600 \mathrm{E}+00$ & $0.00 \mathrm{E}+00$ & $0.00 E+00$ \\
\hline $1.28 \mathrm{E}-02$ & $6.41 E-04$ & 0.01 & $9.400 \mathrm{E}-03$ & $6 E-02$ & $0.00 E+00$ & $0.00 \mathrm{E}+00$ & & $9.400 \mathrm{E}-03$ & $0.00 E+00$ & $0.00 E+00$ \\
\hline $1.27 E-02$ & $6.34 \mathrm{E}-04$ & 0.01 & $9.400 \mathrm{E}-03$ & $6 \mathrm{E}-02$ & $0.00 \mathrm{E}+00$ & $0.00 E+00$ & & $9.400 E-03$ & $0.00 E+00$ & $.00 E+00$ \\
\hline $2.37 \mathrm{E}-02$ & $1.18 \mathrm{E}-03$ & 0.01 & $9.400 \mathrm{E}-02$ & $6 \mathrm{E}-02$ & $0.00 E+00$ & $O E+00$ & & $9.400 \mathrm{E}-02$ & $0 \mathrm{E}+00$ & $E+00$ \\
\hline $2.51 E-02$ & $1.25 E$ & & $0 \mathrm{E}-02$ & $6 E-02$ & $0.00 E+00$ & $0.00 E+00$ & EE-02 & $9.400 \mathrm{E}-02$ & $E+00$ & $E+00$ \\
\hline 5.7 & $2.87 \mathrm{E} .03$ & 0.01 & $E-01$ & $6 \mathrm{E}-02$ & $0.00 E+00$ & $0.00 E+00$ & -02 & DOE-01 & $0.00 E+00$ & $0.00 E+00$ \\
\hline $5.72 \mathrm{E}-02$ & $2.86 \mathrm{E}-03$ & 0.01 & $4.700 \mathrm{E}-01$ & $6 \mathrm{E}-02$ & $0.00 E+00$ & $E+00$ & & $E-01$ & $0.00 E+00$ & +00 \\
\hline $8.59 \mathrm{E}-02$ & $4.30 E-03$ & 0.01 & OE-01 & $6 \mathrm{E}-02$ & $0 E+00$ & $E+00$ & & OE-01 & $0.00 E+00$ & +00 \\
\hline $8.76 E-02$ & $4.38 E-03$ & 0.01 & $9.400 E-01$ & $6 \mathrm{E}-02$ & $0.00 E+00$ & $\mathrm{E}+00$ & .02 & $9.400 \mathrm{E}-01$ & $0.00 E+00$ & $E+00$ \\
\hline 1.19E-01 & $5.95 \mathrm{E}-03$ & 0.01 & $2.162 E+00$ & $6 \mathrm{E}-02$ & $0.00 E+00$ & $0.00 \mathrm{E}+00$ & -02 & $2.162 E+00$ & $0.00 E+00$ & $0.00 E+00$ \\
\hline $1.24 E-01$ & $6.19 E-03$ & 0.01 & $2.162 E+00$ & $6 \mathrm{E}-02$ & $0.00 E+00$ & $0.00 E+00$ & 6.00 & $2.162 E+00$ & $0.00 E+00$ & $E+00$ \\
\hline $1.51 \mathrm{E}-01$ & $7.53 E-03$ & 0.01 & $4.230 E+00$ & $6 E-02$ & $0.00 E+00$ & $0.00 E+00$ & $6.00 \mathrm{E}-02$ & $4.230 E+00$ & $0.00 E+00$ & $0.00 E+00$ \\
\hline 1.53E-01 & $7.66 \mathrm{E}-03$ & 0.01 & $4.230 \mathrm{E}+00$ & $6 \mathrm{E}-02$ & $0.00 E+00$ & $0.00 E+00$ & $6.00 E-02$ & $4.230 E+00$ & $0.00 E+00$ & $0.00 E+00$ \\
\hline $1.46 \mathrm{E}-01$ & $7.30 \mathrm{E}-03$ & 0.01 & $5.152 E+00$ & $6 \mathrm{E}-02$ & $0.00 E+00$ & $0.00 E+00$ & $6.00 \mathrm{E}-02$ & $5.152 E+00$ & $0.00 \mathrm{E}+00$ & $0.00 E+00$ \\
\hline $1.50 \mathrm{E}-01$ & $7.52 E-03$ & 0.01 & $5.152 E+00$ & $6 E-02$ & $0.00 E+00$ & $0.00 E+00$ & $6.00 \mathrm{E}-02$ & $5.152 E+00$ & $0.00 E+00$ & $0.00 E+00$ \\
\hline $4.04 \mathrm{E}-02$ & $2.02 \mathrm{E}-03$ & 0.01 & $5.60 E+00$ & $6 \mathrm{E}-02$ & $5.00 \mathrm{E}-04$ & $0.00 E+00$ & $5.6605 E+00$ & $0.00 \mathrm{E}+00$ & $0.00 E+00$ & $0.00 E+00$ \\
\hline 3.87E-02 & $1.94 \mathrm{E}-03$ & 0.01 & $5.60 E+00$ & $6 \mathrm{E}-02$ & $5.00 \mathrm{E}-04$ & $0.00 E+00$ & $5.6605 E+00$ & $0.00 E+00$ & $0.00 \mathrm{E}+00$ & $0.00 E+00$ \\
\hline $5.19 \mathrm{E}-02$ & $2.59 \mathrm{E}-03$ & 0.01 & $5.60 E+00$ & $6 \mathrm{E}-02$ & $5.00 \mathrm{E}-04$ & $0.00 E+00$ & $5.1005 \mathrm{E}+00$ & $5.60 \mathrm{E}-01$ & $0.00 E+00$ & $0.00 E+00$ \\
\hline 5.31E-02 & $2.66 \mathrm{E}-03$ & 0.01 & $5.60 E+00$ & $6 \mathrm{E}-02$ & $5.00 \mathrm{E}-04$ & $0.00 E+00$ & $5.1005 E+00$ & $5.60 \mathrm{E}-01$ & $0.00 E+00$ & $0.00 E+00$ \\
\hline $6.95 \mathrm{E}-02$ & $3.48 E-03$ & 0.01 & $5.60 \mathrm{E}+00$ & $6 \mathrm{E}-02$ & $5.00 \mathrm{E}-04$ & $0.00 E+00$ & $4.2605 E+00$ & $1.40 \mathrm{E}+00$ & $0.00 E+00$ & $0.00 \mathrm{E}+00$ \\
\hline $7.06 \mathrm{E}-02$ & $3.53 \mathrm{E}-03$ & 0.01 & $5.60 E+00$ & $6 E-02$ & $5.00 E-04$ & $0.00 \mathrm{E}+00$ & $4.2605 E+00$ & $1.40 \mathrm{E}+00$ & $0.00 E+00$ & $0.00 E+00$ \\
\hline 1.07E-01 & $5.37 E-03$ & 0.01 & $5.60 E+00$ & $6 E-02$ & $5.00 E-04$ & $0.00 E+00$ & $2.8605 E+00$ & $2.80 E+00$ & $0.00 E+00$ & $0.00 E+00$ \\
\hline $1.10 \mathrm{E}-01$ & $5.49 \mathrm{E}-03$ & 0.01 & $5.60 \mathrm{E}+00$ & $6 E-02$ & 5.00E-04 & $0.00 E+00$ & $2.8605 E+00$ & $2.80 E+00$ & $0.00 E+00$ & $0.00 E+00$ \\
\hline $1.57 \mathrm{E}-01$ & $7.86 E-03$ & 0.01 & $5.60 E+00$ & $6 \mathrm{E}-02$ & $5.00 \mathrm{E}-04$ & $0.00 E+00$ & $1.4605 E+00$ & $4.20 E+00$ & $0.00 E+00$ & $0.00 E+00$ \\
\hline $1.48 \mathrm{E}-01$ & $7.42 \mathrm{E}-03$ & 0.01 & $5.60 E+.00$ & $6 \mathrm{E}-02$ & $5.00 E-04$ & $0.00 E+00$ & $1.4605 \mathrm{E}+00$ & $4.20 E+00$ & $0.00 E+00$ & $0.00 E+00$ \\
\hline $1.39 \mathrm{E}-01$ & $6.94 \mathrm{E}-03$ & 0.01 & $5.60 E+00$ & $6 \mathrm{E}-02$ & $5.00 E-04$ & $0.00 E+00$ & $6.0500 \mathrm{E}-02$ & $5.60 E+00$ & $0.00 E+00$ & $0.00 E+00$ \\
\hline 1.39E-01 & $6.94 \mathrm{E}-03$ & 0.01 & $5.60 E+00$ & $6 \mathrm{E}-02$ & $5.00 \mathrm{E}-04$ & $0.00 E+00$ & $6.0500 \mathrm{E}-02$ & $5.60 E+00$ & $0.00 E+00$ & $0.00 E+00$ \\
\hline $1.20 \mathrm{E}-01$ & $6.02 E-03$ & 0.01 & $1.00 \mathrm{E}-02$ & $0.00 E+00$ & $5.00 E-04$ & $0.00 E+00$ & 5.0000 E- 04 & $0.00 E+00$ & $1.00 E-02$ & $0.00 \mathrm{E}+00$ \\
\hline
\end{tabular}




\begin{tabular}{|c|c|c|c|c|c|c|c|c|c|c|}
\hline $1.22 \mathrm{E}-01$ & $6.11 \mathrm{E}-03$ & 0.01 & $1.00 E-02$ & $0.00 E+00$ & $5.00 E-04$ & $0.00 E+00$ & $5.0000 \mathrm{E}-04$ & $0.00 \mathrm{E}+00$ & $1.00 \mathrm{E} \cdot 02$ & $0.00 E+00$ \\
\hline $7.62 \mathrm{E}-01$ & $3.81 \mathrm{E}-02$ & 0.01 & $1.00 E-01$ & $0.00 E+00$ & $5.00 E-04$ & $0.00 E+00$ & $5.0000 E-04$ & $0.00 E+00$ & $1.00 \mathrm{E}-01$ & $0.00 E+00$ \\
\hline $7.44 E-01$ & $3.72 \mathrm{E}-02$ & 0.01 & $1.00 \mathrm{E}-01$ & $0.00 E+00$ & $5.00 E-04$ & $0.00 E+00$ & $5.0000 \mathrm{E}-04$ & $0.00 E+00$ & $1.00 \mathrm{E}-01$ & $0.00 E+00$ \\
\hline $2.86 E+00$ & $1.43 \mathrm{E}-01$ & 0.01 & $5.00 \mathrm{E}-01$ & $0.00 E+00$ & $5.00 E-04$ & $0.00 E+00$ & 5.0000 E- 04 & $0.00 E+00$ & $5.00 E-01$ & $0.00 \mathrm{E}+00$ \\
\hline $2.80 E+00$ & $1.40 E-01$ & 0.01 & $5.00 E-01$ & $0.00 E+00$ & $5.00 E-04$ & $0.00 E+00$ & 5.0000 E-04 & $0.00 E+00$ & $5.00 \mathrm{E}-01$ & $0.00 E+00$ \\
\hline $5.06 E+00$ & $2.53 E-01$ & 0.01 & $1.00 E+00$ & $0.00 E+00$ & $5.00 E-04$ & $0.00 E+00$ & $5.0000 \mathrm{E}-04$ & $0.00 E+00$ & $1.00 E+00$ & $0.00 E+00$ \\
\hline $4.97 E+00$ & $2.48 \mathrm{E}-01$ & 0.01 & $1.00 \mathrm{E}+00$ & $0.00 E+00$ & $5.00 E-04$ & $0.00 E+00$ & $5.0000 \mathrm{E}-04$ & $0.00 \mathrm{E}+00$ & $1.00 E+00$ & $0.00 \mathrm{E}+00$ \\
\hline $9.05 E+00$ & $4.52 \mathrm{E}-01$ & 0.01 & $2.25 E+00$ & $0.00 E+00$ & $5.00 E-04$ & $0.00 E+00$ & $5.0000 E-04$ & $0.00 E+00$ & $2.25 \mathrm{E}+00$ & $0.00 E+00$ \\
\hline $9.10 E+00$ & $4.55 \mathrm{E}-01$ & 0.01 & $2.25 \mathrm{E}+00$ & $0.00 \mathrm{E}+00$ & $5.00 E-04$ & $0.00 E+00$ & $5.0000 \mathrm{E}-04$ & $0.00 E+00$ & $2.25 \mathrm{E}+00$ & $0.00 E+00$ \\
\hline $1.34 \mathrm{E}+01$ & $6.70 \mathrm{E}-01$ & 0.01 & $4.50 E+00$ & $0.00 E+00$ & $5.00 \mathrm{E}-04$ & $0.00 E+00$ & $5.0000 \mathrm{E}-04$ & $0.00 E+00$ & $4.50 E+00$ & $0.00 E+00$ \\
\hline $1.32 E+01$ & $6.58 E-01$ & 0.01 & $4.50 \mathrm{E}+00$ & $0.00 E+00$ & $5.00 E .04$ & $0.00 E+00$ & $5.0000 \mathrm{E}-04$ & $0.00 E+00$ & $4.50 \mathrm{E}+00$ & $0.00 E+00$ \\
\hline $1.49 \mathrm{E}+01$ & $7.45 E-01$ & 0.01 & $5.60 E+00$ & $0.00 E+00$ & $5.00 E-04$ & $0.00 E+00$ & $5.0000 \mathrm{E}-04$ & $0.00 E+00$ & $5.60 \mathrm{E}+00$ & $0.00 \mathrm{E}+00$ \\
\hline $1.48 \mathrm{E}+01$ & $7.39 E-01$ & 0.01 & $5.60 E+00$ & $0.00 E+00$ & $5.00 E-04$ & $0.00 E+00$ & $5.0000 \mathrm{E}-04$ & $0.00 E+00$ & $5.60 E+00$ & $0.00 E+00$ \\
\hline $7.96 \mathrm{E}+00$ & $3.98 \mathrm{E}-01$ & 0.01 & $5.60 \mathrm{E}+00$ & $0.00 E+00$ & $5.00 E-04$ & $0.00 E+00$ & $5.6005 E+00$ & $0.00 \mathrm{E}+00$ & $0.00 E+00$ & $0.00 E+00$ \\
\hline $7.84 E+D D$ & $3.92 \mathrm{E}-01$ & 0.01 & $5.60 E+00$ & $0.00 E+00$ & $5.00 E-04$ & $0.00 E+00$ & $5.6005 E+00$ & $0.00 E+00$ & $0.00 E+00$ & $0.00 \mathrm{E}+00$ \\
\hline $1.09 E+01$ & $5.43 \mathrm{E}-01$ & 0.01 & $5.60 \mathrm{E}+00$ & $0.00 E+00$ & $5.00 E-04$ & $0.00 E+00$ & $4.2005 \mathrm{E}+00$ & $0.00 E+00$ & $1.40 \mathrm{E}+00$ & $0.00 E+00$ \\
\hline $1.10 E+01$ & $5.49 E-01$ & 0.01 & $5.60 E+00$ & $0.00 E+00$ & $5.00 \mathrm{E}-04$ & $0.00 E+00$ & $4.2005 E+00$ & $0.00 E+00$ & $1.40 E+00$ & $0.00 E+00$ \\
\hline $1.20 \mathrm{E}+01$ & $6.01 \mathrm{E}-01$ & 0.01 & $5.60 E+00$ & $0.00 E+00$ & $5.00 \mathrm{E}-04$ & $0.00 E+00$ & $2.8005 E+00$ & $0.00 E+00$ & $2.80 E+D 0$ & $0.00 E+00$ \\
\hline $1.19 E+01$ & $5.95 \mathrm{E}-01$ & 0.01 & $5.60 E+00$ & $0.00 E+00$ & $5.00 \mathrm{E}-04$ & $0.00 E+00$ & $2.8005 E+00$ & $0.00 \mathrm{E}+00$ & $2.80 E+00$ & $0.00 E+00$ \\
\hline $1.30 E+01$ & $6.50 \mathrm{E}-01$ & 0.01 & $5.60 E+00$ & $0.00 E+00$ & $5.00 \mathrm{E}-04$ & $0.00 E+00$ & $1.4005 E+00$ & $0.00 E+00$ & $4.20 \mathrm{E}+00$ & $0.00 E+00$ \\
\hline $1.52 E+01$ & $7.62 \mathrm{E}-01$ & 0.01 & $5.60 E+00$ & $0.00 E+00$ & $5.00 E-04$ & $0.00 E+00$ & $1.4005 E+00$ & $0.00 E+00$ & $4.20 E+00$ & $0.00 E+00$ \\
\hline $1.49 E+01$ & $7.45 E-01$ & 0.01 & $5.60 E+00$ & $0.00 E+00$ & $5.00 E-04$ & $0.00 E+00$ & 5.00000 E- 04 & $0.00 E+00$ & $5.60 E+00$ & $0.00 E+00$ \\
\hline $1,4 \mathrm{BE}+01$ & $7.39 \mathrm{E}-01$ & 0.01 & $5.60 \mathrm{E}+00$ & $0.00 E+00$ & $5.00 E-04$ & $0.00 E+00$ & $5.0000 E-04$ & $0.00 E+00$ & $5.60 \mathrm{E}+00$ & $0.00 E+00$ \\
\hline $9.74 \mathrm{E}-03$ & $4.87 E-04$ & 0.01 & $9.40 \mathrm{E}-03$ & $6.00 E-02$ & $0.00 E+00$ & $0.00 \mathrm{E}+00$ & 6.00E-02 & $0.00 E+00$ & 9.400 E-03 & $0.00 E+00$ \\
\hline $9.63 \mathrm{E}-03$ & $4.82 \mathrm{E}-04$ & 0.01 & $9.400 \mathrm{E}-03$ & $6.00 E-02$ & $0.00 E+00$ & $0.00 E+00$ & $6.00 \mathrm{E}-02$ & $0.00 E+00$ & $9.400 \mathrm{E}-03$ & $0.00 \mathrm{E}+00$ \\
\hline $1.30 \mathrm{E}-02$ & $6.51 E-04$ & 0.01 & $9.400 \mathrm{E}-02$ & $6.00 \mathrm{E}-02$ & $0.00 E+00$ & $0.00 E+00$ & $E-02$ & $0.00 E+00$ & $9.400 \mathrm{E}-02$ & $0.00 \mathrm{E}+00$ \\
\hline $1.30 \mathrm{E} \cdot 02$ & $6.51 \mathrm{E}-04$ & 0.01 & $9.400 \mathrm{E}-02$ & $6.00 \mathrm{E}-02$ & $0.00 \mathrm{E}+00$ & $0.00 E+00$ & $6.00 E-02$ & $0.00 E+00$ & 9.400E-02 & $0.00 E+00$ \\
\hline $2.38 \mathrm{E}-02$ & $1.19 \mathrm{E}-03$ & 0.01 & $4.700 E-01$ & $6.00 \mathrm{E}-02$ & $0.00 \mathrm{E}+00$ & $0.00 E+00$ & $E-02$ & $0.00 E+00$ & $4.700 E-01$ & $0.00 E+00$ \\
\hline $2.40 E-02$ & $1.20 \mathrm{E}-03$ & 0.01 & $4.700 E-01$ & $6.00 \mathrm{E}-02$ & $0.00 \mathrm{E}+00$ & $0.00 \mathrm{E}+00$ & $6.00 E-02$ & $0.00 E+00$ & $4.700 E-01$ & $0.00 E+00$ \\
\hline $3.37 E-02$ & $1.68 \mathrm{E}-03$ & 0.01 & $9.400 \mathrm{E}-01$ & $6.00 \mathrm{E}-02$ & $0.00 E+00$ & $0.00 E+00$ & $E-02$ & $0.00 E+00$ & $9.400 \mathrm{E} \cdot 01$ & $0.00 E+00$ \\
\hline $3.34 \mathrm{E}-02$ & $1.67 E-03$ & 0.01 & $9.400 E-01$ & $6.00 \mathrm{E}-02$ & $0.00 E+00$ & $0.00 E+00$ & $6.00 E-02$ & $0.00 E+00$ & $9.400 \mathrm{E}-01$ & $0.00 E+00$ \\
\hline & & 0.01 & $2.162 E+00$ & $6.00 \mathrm{E}-02$ & $0.00 \mathrm{E}+00$ & $E+00$ & & $0.00 E+00$ & $2.162 E+00$ & $0.00 E+00$ \\
\hline $4.96 \mathrm{E}-02$ & $2.48 \mathrm{E}-03$ & 0.01 & $2.162 E+00$ & $6.00 E-02$ & $0.00 \mathrm{E}+00$ & $0.00 \mathrm{E}+00$ & $6.00 E-02$ & $0.00 E+00$ & $2.162 E+00$ & $0.00 E+00$ \\
\hline $6.45 \mathrm{E}-02$ & 3.23 & 0.01 & $4.230 E+00$ & $6.00 E-02$ & $E+00$ & $0.00 E+00$ & & $0.00 E+00$ & $4.230 E+00$ & $0.00 E+00$ \\
\hline $6.47 E-02$ & $3.23 \mathrm{E}-03$ & 0.01 & $4.230 \mathrm{E}+00$ & $6.00 \mathrm{E}-02$ & $0.00 E+00$ & $0.00 E+00$ & $6.00 \mathrm{E}-02$ & $0.00 E+00$ & $4.230 E+00$ & $0.00 E+00$ \\
\hline $6.74 \mathrm{E}-02$ & $3.37 \mathrm{E}-03$ & 0.01 & $2 E+00$ & $6.00 \mathrm{E}-02$ & $0.00 \mathrm{E}+00$ & $0.00 \mathrm{E}+00$ & $E-02$ & $0.00 E+00$ & $5.152 \mathrm{E}+00$ & $0.00 E+00$ \\
\hline $6.65 \mathrm{E}-02$ & $3.33 \mathrm{E}-03$ & 0.01 & $5.152 E+00$ & $6.00 \mathrm{E}-02$ & $0.00 E+00$ & $0.00 E+00$ & $6.00 E-02$ & $0.00 E+00$ & $5.152 E+00$ & $0.00 E+00$ \\
\hline $5.36 \mathrm{E}-02$ & $2.68 \mathrm{E}-03$ & 0.01 & 1.00 & $0.00 E+00$ & $5.00 \mathrm{E}-04$ & $0.00 \mathrm{E}+00$ & OOOE-04 & $0.00 E+00$ & $0.00 E+00$ & $1.00 \mathrm{E}-02$ \\
\hline $5.49 \mathrm{E}-02$ & $2.75 E-03$ & 0.01 & $1.00 \mathrm{E}-02$ & $0.00 E+00$ & $5.00 E-04$ & $0.00 E+00$ & 5.0000 E-04 & $0.00 E+00$ & $0.00 E+00$ & $1.00 \mathrm{E}-02$ \\
\hline $2.51 \mathrm{E}-01$ & $1.26 \mathrm{E}-02$ & 0.01 & $1.00 \mathrm{E}-01$ & $0.00 E+00$ & $5.00 E-04$ & $0.00 E+00$ & $5.0000 E-04$ & $E+00$ & $0.00 E+00$ & $E-01$ \\
\hline $2.45 E-01$ & $1.22 \mathrm{E}-02$ & 0.01 & $1.00 \mathrm{E}-01$ & $0.00 E+00$ & $5.00 E-04$ & $0.00 E+00$ & $5.0000 \mathrm{E}-04$ & $0.00 E+00$ & $0.00 E+00$ & $1.00 \mathrm{E}-01$ \\
\hline $7.85 E-01$ & $3.92 E-02$ & 0.01 & 5.001 & $0.00 E+00$ & $5.00 E-04$ & $0.00 E+00$ & $00 E-04$ & $E+00$ & $E+00$ & E-01 \\
\hline $7.98 \mathrm{E}-01$ & $3.99 \mathrm{E}-02$ & 0.01 & $5.00 E-01$ & $0.00 E+00$ & $5.00 E-04$ & $0.00 E+00$ & $5.0000 \mathrm{E}-04$ & $0.00 E+00$ & $0.00 E+00$ & $5.00 E-01$ \\
\hline $130 E+00$ & $6.51 \mathrm{E}-02$ & 0.01 & $1.00 E+00$ & $0.00 E+00$ & $5.00 \mathrm{E}-04$ & $0.00 E+00$ & $5.0000 \mathrm{E}-04$ & $0.00 E+00$ & $0.00 E+00$ & $1.00 E+00$ \\
\hline $1.31 E+00$ & & 0.01 & & $0.00 E+00$ & & & DOE-O4 & $0.00 \mathrm{E}+00$ & $E+00$ & \\
\hline $2.54 E+00$ & $1.27 \mathrm{E}-01$ & 0.01 & $2.25 E+00$ & $0.00 E+00$ & $5.00 E-04$ & $0.00 E+00$ & $5.0000 \mathrm{E}-04$ & $0.00 E+00$ & $0.00 E+00$ & $2.25 E+00$ \\
\hline $2.41 E+00$ & $1.20 \mathrm{E}-01$ & 0.01 & $2.25 \mathrm{E}+00$ & $0.00 E+00$ & $5.00 \mathrm{E}-04$ & & $5.0000 \mathrm{E}-04$ & & $\mathrm{E}+00$ & \\
\hline $4.39 E+00$ & $2.19 \mathrm{E}-01$ & 0.01 & $4.50 \mathrm{E}+00$ & $0.00 E+00$ & $5.00 E-04$ & $0.00 E+00$ & $5.0000 \mathrm{E}-04$ & $0.00 E+00$ & $0.00 E+00$ & $4.50 E+00$ \\
\hline $4.38 E+00$ & $2.19 \mathrm{E}-01$ & 0.01 & $4.50 E+00$ & $0.00 E+00$ & $5.00 E-04$ & $0.00 E+00$ & $5.0000 E-04$ & $0.00 E+00$ & $0.00 E+00$ & $4.50 E+00$ \\
\hline $7.96 \mathrm{E}+00$ & $3.98 \mathrm{E}-01$ & 0.01 & $5.60 E+00$ & $0.00 E+00$ & $5.00 E-04$ & $0.00 E+00$ & $5.6005 E+00$ & $0.00 E+00$ & $0.00 E+00$ & $0.00 E+00$ \\
\hline $7.84 E+00$ & $3.92 \mathrm{E}-01$ & 0.01 & $5.60 E+00$ & $0.00 E+00$ & $5.00 \mathrm{E}-04$ & $0.00 E+00$ & $5.6005 \mathrm{E}+00$ & & & \\
\hline $9.92 \mathrm{E}+00$ & $4.96 \mathrm{E}-01$ & 0.01 & $5.60 \mathrm{E}+00$ & $0.00 \mathrm{E}+00$ & $5.00 E-04$ & $0.00 \mathrm{E}+00$ & $4.2005 \mathrm{E}+00$ & $0.00 E+00$ & $0.00 E+00$ & $1.40 E+00$ \\
\hline $1.02 E+01$ & $5.09 \mathrm{E}-01$ & 0.01 & $5.60 E+00$ & & $5.00 \mathrm{E}-04$ & $0.00 E+00$ & & $0.00 E+00$ & $0.00 E+00$ & $1.40 E+00$ \\
\hline $9.57 \mathrm{E}+00$ & $4.79 \mathrm{E}-01$ & 0.01 & $5.60 E+00$ & $0.00 E+00$ & $5.00 \mathrm{E}-04$ & $0.00 E+00$ & $2.8005 E+00$ & $0.00 E+00$ & $0.00 E+00$ & $2.80 E+00$ \\
\hline $9.37 E+00$ & $4.69 \mathrm{E}-01$ & 0.01 & $5.60 E+00$ & $0.00 E+00$ & $5.00 \mathrm{E}-04$ & $0.00 E+00$ & $2.8005 E+00$ & $0.00 E+00$ & $0.00 \mathrm{E}+00$ & $2.80 E+00$ \\
\hline $7.82 E+00$ & $3.91 E-01$ & 0.01 & $5.60 E+00$ & $0.00 E+00$ & $5.00 E-04$ & & $1.4005 \mathrm{E}+00$ & $0.00 E+00$ & $E+00$ & $4.20 \mathrm{E}+00$ \\
\hline $7.60 E+00$ & $3.80 E-01$ & 0.01 & $5.60 \mathrm{E}+00$ & $0.00 E+00$ & $5.00 E-04$ & $0.00 E+00$ & $1.4005 E+00$ & $0.00 E+00$ & $0.00 E+00$ & $4.20 E+00$ \\
\hline $6.36 \mathrm{E}+00$ & $3.18 E-01$ & 0.01 & $5.60 \mathrm{E}+00$ & & $5.00 \mathrm{E}-04$ & & $5.0000 \mathrm{E} \cdot 04$ & & $0.00 E+00$ & $5.04 E+00$ \\
\hline $6.61 \mathrm{E}+00$ & $3.31 \mathrm{E}-01$ & 0.01 & $5.60 E+00$ & $0.00 E+00$ & $5.00 \mathrm{E}-04$ & $0.00 E+00$ & $5.0000 E-04$ & $5.60 E-01$ & $0.00 E+00$ & $5.04 E+00$ \\
\hline $9.68 \mathrm{E}+00$ & $4.84 \mathrm{E}-01$ & 0.01 & $5.60 E+00$ & & $5.00 \mathrm{E}-04$ & & $5.0000 E-04$ & & $0.00 E+00$ & $4.20 \mathrm{E}+00$ \\
\hline $9.55 E+00$ & $4.788-01$ & 0.01 & $5.60 E+00$ & $0.00 E+00$ & $5.00 \mathrm{E}-04$ & $0.00 E+00$ & $5.0000 \mathrm{E}-04$ & $1.40 E+00$ & $0.00 E+00$ & $4.20 E+00$ \\
\hline $2.16 E+01$ & $1.08 E+00$ & 0.01 & $5.60 E+00$ & $0.00 E+00$ & $5.00 E-04$ & $0.00 E+00$ & $5.00000 E-04$ & $2.80 E+00$ & & \\
\hline $2.07 E+01$ & $1.03 E+00$ & 0.01 & $5.60 \mathrm{E}+00$ & $0.00 \mathrm{E}+00$ & $5.00 E-04$ & $0.00 E+00$ & $5.0000 E-04$ & $2.80 E+00$ & $0.00 E+00$ & $2.80 E+00$ \\
\hline $4.36 E+01$ & $2.18 \mathrm{E}+00$ & 0.01 & $5.60 E+00$ & $0.00 E+00$ & $5.00 E-04$ & $0.00 E+00$ & $5.0000 \mathrm{E}-04$ & $4.20 E+00$ & $0.00 E+00$ & $1.40 E+00$ \\
\hline
\end{tabular}




\begin{tabular}{|c|c|c|c|c|c|c|c|c|c|c|}
\hline $4.86 \mathrm{E}+01$ & $2.43 \mathrm{E}+00$ & 0.01 & $5.60 E+00$ & $0.00 E+00$ & $5.00 \mathrm{E}-04$ & $0.00 E+00$ & 5.0000E-04 & 4.20E+00 & $0.00 E+00$ & $1.40 \mathrm{E}+00$ \\
\hline $1.02 E+02$ & $5.12 E+00$ & 0.01 & $5.60 \mathrm{E}+00$ & $0.00 E+00$ & 5.00 E-04 & $0.00 \mathrm{E}+00$ & $5.0000 E-04$ & $5.60 E+00$ & $0.00 \mathrm{E}+00$ & $0.00 E+00$ \\
\hline $9.88 E+01$ & $4.94 E+00$ & 0.01 & $5.60 E+00$ & $0.00 E+00$ & $5.00 E-04$ & $0.00 E+00$ & $5.0000 \mathrm{E}-04$ & $5.60 E+00$ & $0.00 E+00$ & $0.00 E+00$ \\
\hline $8.91 E-03$ & $4.45 E-04$ & 0.01 & $1.000 \mathrm{E}-02$ & $6.00 \mathrm{E}-02$ & $5.00 E-04$ & $0.00 E+00$ & $6.05 \mathrm{E}-02$ & $0.00 E+00$ & $0.00 E+00$ & $1.000 \mathrm{E}-02$ \\
\hline $8.92 \mathrm{E}-03$ & $4.46 \mathrm{E}-04$ & 0.01 & $1.000 E-02$ & $6.00 \mathrm{E}-02$ & $5.00 \mathrm{E}-04$ & $0.00 E+00$ & $6.05 \mathrm{E}-02$ & $0.00 E+00$ & $0.00 E+00$ & $1.000 E-02$ \\
\hline 9.37E-03 & $4.69 E-04$ & 0.01 & $1.000 \mathrm{E}-01$ & $6.00 \mathrm{E}-02$ & $5.00 \mathrm{E}-04$ & $0.00 E+00$ & $6.05 \mathrm{E}-02$ & $0.00 E+00$ & $0.00 E+00$ & $1.000 E=01$ \\
\hline $9.54 E-03$ & 4.77E-04 & 0.01 & 1.000E-01 & $6.00 \mathrm{E}-02$ & $5.00 E-04$ & $0.00 E+00$ & $6.05 \mathrm{E}-02$ & $0.00 E+00$ & $0.00 E+00$ & $1.000 \mathrm{E}-01$ \\
\hline $1.27 E-02$ & $6.37 \mathrm{E}-04$ & 0.01 & 5.000 E-01 & $6.00 \mathrm{E}-02$ & 5.00E-D4 & $0.00 \mathrm{E}+00$ & $6.05 \mathrm{E}-02$ & $0.00 E+00$ & $0.00 E+00$ & 5.000E-01 \\
\hline $1.30 E-02$ & $6.49 E-04$ & 0.01 & 5.000 E- 01 & $6.00 \mathrm{E}-02$ & $5.00 \mathrm{E}-04$ & $0.00 E+00$ & $6.05 \mathrm{E}-02$ & $0.00 E+00$ & $0.00 E+00$ & $5.000 \mathrm{E}-01$ \\
\hline $1.69 E-02$ & $8.47 E-04$ & 0.01 & $1.000 E+00$ & $6.00 \mathrm{E}-02$ & 5.00E-04 & $0.00 E+00$ & 6.05E-02 & $0.00 \mathrm{E}+00$ & $0.00 E+00$ & $1.000 E+00$ \\
\hline $1.69 E-02$ & $8.44 E-04$ & 0.01 & $1.000 E+00$ & $6.00 E-02$ & $5.00 E-04$ & $0.00 \mathrm{E}+00$ & $6.05 \mathrm{E}-02$ & $0.00 E+00$ & $0.00 E+00$ & $1.000 E+00$ \\
\hline $2.73 \mathrm{E}-02$ & $1.36 \mathrm{E}-03$ & 0.01 & $2.250 E+00$ & 6.00E-02 & $5.00 \mathrm{E}-04$ & $0.00 E+00$ & $6.05 E-02$ & $0.00 E+00$ & $0.00 E+00$ & $2.250 E+00$ \\
\hline $2.69 \mathrm{E}-02$ & $1.35 E-03$ & 0.01 & $2.250 E+00$ & $6.00 \mathrm{E}-02$ & $5.00 \mathrm{E}-04$ & $0.00 E+00$ & $6.05 E-02$ & $0.00 E+00$ & $0.00 E+00$ & $2.250 E+00$ \\
\hline $4.44 E-02$ & $2.22 \mathrm{E}-03$ & 0.01 & $4.500 E+00$ & $6.00 \mathrm{E}-02$ & $5.00 E-04$ & $0.00 E+00$ & $6.05 E-02$ & $0.00 E+00$ & $0.00 E+00$ & $4.500 E+00$ \\
\hline $4.45 E-02$ & $2.22 \mathrm{E}-03$ & 0.01 & $4.500 E+00$ & $6.00 \mathrm{E}-02$ & $5.00 \mathrm{E}-04$ & $0.00 E+00$ & $6.05 \mathrm{E}-02$ & $0.00 E+00$ & $0.00 E+00$ & $4.500 E+00$ \\
\hline $9.18 \mathrm{E}-03$ & $4.59 \mathrm{E}-04$ & 0.01 & $9.400 \mathrm{E}-03$ & $6.00 E-02$ & $0.00 E+00$ & $0.00 E+00$ & $6.00 \mathrm{E}-02$ & $0.00 E+00$ & $0.00 E+00$ & $9.400 E-03$ \\
\hline $9.12 \mathrm{E}-03$ & $4.56 \mathrm{E}-04$ & 0.01 & $9.400 \mathrm{E}-03$ & $6.00 E-02$ & $0.00 E+00$ & $0.00 E+00$ & $6.00 E-02$ & $0.00 E+00$ & $0.00 E+00$ & 9.400 E-03 \\
\hline $9.66 \mathrm{E}-03$ & $4.83 E-04$ & 0.01 & $9.400 \mathrm{E}-02$ & $6.00 E-02$ & $0.00 E+00$ & $0.00 E+00$ & $6.00 E-02$ & $0.00 E+00$ & $0.00 E+00$ & $9.400 E-02$ \\
\hline $9.67 E-03$ & $4.84 \mathrm{E}-04$ & 0.01 & $9.400 \mathrm{E}-02$ & $6.00 \mathrm{E}-02$ & $0.00 E+00$ & $0.00 E+00$ & 6.00 E- 02 & $0.00 E+00$ & $0.00 E+00$ & $9.400 \mathrm{E}-02$ \\
\hline 1.33E-02 & $6.63 E-04$ & 0.01 & $4.700 \mathrm{E}-01$ & $6.00 \mathrm{E}-02$ & $0.00 E+00$ & $0.00 E+00$ & $6.00 \mathrm{E}-02$ & $0.00 E+00$ & $0.00 E+00$ & $4.700 \mathrm{E}-01$ \\
\hline 1.33E-02 & $6.64 \mathrm{E}-04$ & 0.01 & $4.700 E-01$ & $6.00 \mathrm{E}-02$ & $0.00 E+00$ & $0.00 E+00$ & $6.00 E-02$ & $0.00 E+00$ & $0.00 E+00$ & 4.700E-01 \\
\hline $1.76 E-02$ & 8.79E-04 & 0.01 & $9.400 \mathrm{E}-01$ & $6.00 \mathrm{E}-02$ & $0.00 E+00$ & $0.00 E+00$ & $6.00 \mathrm{E}-02$ & $0.00 \mathrm{E}+00$ & $0.00 E+00$ & $9.400 E-01$ \\
\hline $1.76 \mathrm{E}-02$ & $8.79 E-04$ & 0.01 & $9.400 \mathrm{E}-01$ & $6.00 E-02$ & $0.00 \mathrm{E}+00$ & $0.00 \mathrm{E}+00$ & $6.00 E-02$ & $0.00 E+00$ & $0.00 E+00$ & $9.400 E-01$ \\
\hline $2.80 E-02$ & $1.40 E-03$ & 0.01 & $2.162 \mathrm{E}+00$ & $6.00 \mathrm{E}-02$ & $0.00 \mathrm{E}+00$ & $0.00 \mathrm{E}+00$ & $6.00 \mathrm{E}-02$ & $0.00 E+00$ & $0.00 E+00$ & $2.162 E+00$ \\
\hline $2.78 \mathrm{E}-02$ & $1.39 \mathrm{E}-03$ & 0.01 & $2.162 \mathrm{E}+00$ & $6.00 \mathrm{E}-02$ & $0.00 E+00$ & $0.00 \mathrm{E}+00$ & 6.00E-02 & $0.00 E+00$ & $0.00 E+00$ & $2.162 E+00$ \\
\hline 4.64E-02 & $2.32 \mathrm{E}-03$ & 0.01 & $4.230 E+00$ & $6.00 E-02$ & $0.00 E+00$ & $0.00 E+00$ & $6.00 \mathrm{E}-02$ & $0.00 E+00$ & $0.00 E+00$ & $4.230 E+00$ \\
\hline $4.64 \mathrm{E}-02$ & $2.32 E-03$ & 0.01 & $4.230 E+00$ & $6.00 \mathrm{E}-02$ & $0.00 E+00$ & $0.00 E+00$ & $6.00 \mathrm{E}-02$ & $0.00 E+00$ & $0.00 E+00$ & $4.230 E+00$ \\
\hline
\end{tabular}




\section{INTERNAL DISTRIBUTION}

1. K. K. Anderson

2. J. F. Birdwell, Jr.

3. P. V. Bonnesen

4. J. L. Collins

5. R. L. Cummins

6-8. L. H. Delmau

9. R. D. Hunt

10. R. T. Jubin

11. T. J. Keever

12. T.E. Kent

13. L. N. Klatt

14. D. D. Lee

15. T. G. Levitskaia

16. M. P. Maskarinec

17. A. J. Mattus

18. C. P. McGinnis

19. L. E. McNeese

20. B. A. Moyer

21. F. V. Sloop, Jr.

22. R. D. Spence

23. J. F. Walker

24. J. S. Watson

25. ORNL Central Research Library

26. Laboratory Records, RC

27. Laboratory Records, OSTI

\section{EXTERNAL DISTRIBUTION}

28. J. T. Carter, Westinghouse Savannah River Company, P.O. Box 616, Buidling 704-3B, Aiken, SC 29808

29. D. Chamberlain, Argonne National Laboratory, Building 205, 9700 South Cass Avenue, Argonne, IL 60439

30. N. F. Chapman, Westinghouse Savannah River Company, P.O. Box 616, Buidling 704-3B, Aiken, SC 29808

31. C. Conner, Argonne National Laboratory, Building 205, 9700 South Cass Avenue, Argonne, IL 60439

32. R. G. Edwards, Westinghouse Savannah River Company, P.O. Box 616, Buidling 704-3B, Aiken, SC 29808

33. S. D. Fink, Westinghouse Savannah River Company, P.O. Box 616, Building 773-A, Aiken, SC 29808

34. H. D. Harmon, Tank Focus Area Salt Processing Program, P.O. Box 616, Building 704-3N, Aiken, SC 29808 
35. R. T. Jones, Westinghouse Savannah River Company, P.O. Box 616, Building 704-3N, Aiken, SC 29808

36. R. A. Leonard, Argonne National Laboratory, Building 205, 9700 South Cass Avenue, Argonne, IL 60439

37. J. W. McCullough, Jr., U.S. Department of Energy, Savannah River Operations Office, Bldg. 704-3N, Aiken, SC 29808

38. J. R. Noble-Dial, U.S. Department of Energy, Oak Ridge Operations Office, P.O. Box 2001, Oak Ridge, TN 37831-8620

39. Michael Norato, Westinghouse Savannah River Company, P.O. Box 616, Building 773-A, Aiken, SC 29808

40. Robert Pierce, Westinghouse Savannah River Company, P.O. Box 616, Building 773-A, Aiken, SC 29808

41. S. N. Schlahta, Tank Focus Area Salt Processing Program, P. O. Box 616, Building 704-3N, Aiken, SC 29808

42. P. C. Suggs, U.S. Department of Energy, Savannah River Operations Office, P.O. Box A, Building 704-3N, Aiken, SC 29808

43. W. L. Tamosaitis, Westinghouse Savannah River Company, P.O. Box 616, Building 773-A, Aiken, SC 29808

44. M. Thompson, Westinghouse Savannah River Company, P.O. Box 616, Building 773-A, Aiken, SC 29808

45. T. A. Todd, Idaho National Engineering \& Environmental Laboratory, Building 637, MS-5218, Idaho Falls, ID 834415-5218

46. G. Vandegrift, Argonne National Laboratory, Building 205, 9700 South Cass Avenue, Argonne, IL 60439

47. Doug Walker, Westinghouse Savannah River Company, P.O. Box 616, Building 773-A, Aiken, SC 29808

48. Dennis Wester, Westinghouse Savannah River Company, P.O. Box 616, Building 773-A, Aiken, SC 29808

49. W. R. Wilmarth, Westinghouse Savannah River Company, P.O. Box 616, Building 773-A, Aiken, SC 29808

50. Tanks Focus Area Technical Team, c/o B. J. Williams, Pacific Northwest National Laboratory, P.O. Box 999, MSIN K9-69, Richland, WA 99352

51. Tanks Focus Area Field Lead, clo T. P. Pietrok, U.S. Department of Energy, Richland Operations Office, P.O. Box 550, K8-50, Richland, WA 99352 
52. Tanks Focus Area Headquarters Program Manager, c/o K. D. Gerdes, DOE Office of Science and Technology, 19901 Germantown Rd., 1154 Cloverleaf Building, Germantown, MD 20874-1290

53. Nicole Simon and Jean-François Dozol, CEA Cadarache, DESD/SEP/LPTE, Bat.326, 13108 St Paul lez Durance Cedex, France

54. Charles Madic, CEA Valrhô-Marcoule, DCC, BP 171, 30207 Bagnols s/Ceze Cedex, France

55. Christophe Douche, CEA Valduc, Is sur Tille, 21120 France 
